\title{
Fluorescent Probes and Selective Inhibitors for Biological Studies of Hydrogen Sulfide- and Polysulfide-Mediated Signaling
}

\author{
Yoko Takano, Honami Echizen, and Kenjiro Hanaoka
}

\begin{abstract}
Significance: Hydrogen sulfide $\left(\mathrm{H}_{2} \mathrm{~S}\right)$ plays roles in many physiological processes, including relaxation of vascular smooth muscles, mediation of neurotransmission, inhibition of insulin signaling, and regulation of inflammation. Also, hydropersulfide $(\mathrm{R}-\mathrm{S}-\mathrm{SH})$ and polysulfide $\left(-\mathrm{S}-\mathrm{S}_{\mathrm{n}}-\mathrm{S}-\right)$ have recently been identified as reactive sulfur species (RSS) that regulate the bioactivities of multiple proteins via $S$-sulfhydration of cysteine residues (protein Cys-SSH) and show cytoprotection. Chemical tools such as fluorescent probes and selective inhibitors are needed to establish in detail the physiological roles of $\mathrm{H}_{2} \mathrm{~S}$ and polysulfide.

Recent Advances: Although many fluorescent probes for $\mathrm{H}_{2} \mathrm{~S}$ are available, fluorescent probes for hydropersulfide and polysulfide have only recently been developed and used to detect these sulfur species in living cells.

Critical Issues: In this review, we summarize recent progress in developing chemical tools for the study of $\mathrm{H}_{2} \mathrm{~S}$, hydropersulfide, and polysulfide, covering fluorescent probes based on various design strategies and selective inhibitors of $\mathrm{H}_{2} \mathrm{~S}$ - and polysulfide-producing enzymes (cystathionine $\gamma$-lyase, cystathionine $\beta$-synthase, and 3mercaptopyruvate sulfurtransferase), and we summarize their applications in biological studies.

Future Directions: Despite recent progress, the precise biological functions of $\mathrm{H}_{2} \mathrm{~S}$, hydropersulfide, and polysulfide remain to be fully established. Fluorescent probes and selective inhibitors are effective chemical tools to study the physiological roles of these sulfur molecules in living cells and tissues. Therefore, further development of a broad range of practical fluorescent probes and selective inhibitors as tools for studies of RSS biology is currently attracting great interest. Antioxid. Redox Signal. 27, 669-683.
\end{abstract}

Keywords: reactive sulfur species, fluorescence imaging, inhibitors

\section{Introduction}

$\mathbf{H}$ YDROGEN SULFIDE $\left(\mathrm{H}_{2} \mathrm{~S}\right)$ IS a toxic gas smelling of rotten eggs, but it has been reported to function in many physiological processes, including relaxation of vascular smooth muscles $(60,85)$, mediation of neurotransmission $(1,40)$, inhibition of insulin signaling (38), and regulation of inflammation $(19,45)$. More recently, reactive sulfur species (RSS) such as hydropersulfide $(\mathrm{R}-\mathrm{S}-\mathrm{SH})$ and polysulfide $\left(-\mathrm{S}-\mathrm{S}_{\mathrm{n}}-\mathrm{S}-\right)$ were also found to have roles in regulating the activity of proteins via $S$-sulfhydration of cysteine (Cys) residues $(\mathrm{SH} \rightarrow \mathrm{SSH})(55,60)$ and the modification of synaptic transmission (41), in addition to a cytoprotective effect (42).

Since $\mathrm{H}_{2} \mathrm{~S}$, polysulfide and hydropersulfide are redox partners, they should coexist in biological systems. In contrast, hydropersulfide and polysulfide seem likely to be much more

(C) Yoko Takano, et al., 2017; Published by Mary Ann Liebert, Inc. This article is available under the Creative Commons License CCBY-NC (http://creativecommons.org/licenses/by-nc/4.0). This license permits non-commercial use, distribution and reproduction in any medium, provided the original work is properly cited. Permission only needs to be obtained for commercial use and can be done via RightsLink. 
effective than $\mathrm{H}_{2} \mathrm{~S}$ in $S$-sulfhydration from the view point of chemical reactivity (76), although the source of the persulfide donor whether its relationship with $\mathrm{H}_{2} \mathrm{~S}$ is as a product or precursor is controversial (84).

There are several methods for selective detection of $\mathrm{H}_{2} \mathrm{~S}$, and the most commonly used are the methylene blue method (44), the sulfide-selective electrode method (77), the monobromobimane method $(43,57)$, and fluorescence detection (74). The monobromobimane method, that is, liquid chromatography mass spectrometry analysis of sulfur compounds labeled with monobromobimane, is also applicable to the detection of hydropersulfide and polysulfide (36). However, homogenization of biological samples is required in these methods, except for fluorescence detection, so they cannot be applied to living cells and tissues.

In contrast, fluorescent probes are easy to use, and enable real-time, nondestructive detection in living cells and tissues $(25,78)$; consequently they have been widely used in biological research to study the physiological functions of $\mathrm{H}_{2} \mathrm{~S}$, hydropersulfide, and polysulfide $(71,74)$. Many selective fluorescent probes for $\mathrm{H}_{2} \mathrm{~S}$ have been reported, and more recently, fluorescent probes for hydropersulfide and polysulfide have also been developed $(47,71,74,87)$.

To study the role of $\mathrm{H}_{2} \mathrm{~S}$, hydropersulfide, and polysulfide in biological systems, several techniques to block the production of these sulfur molecules have been employed. For examples, mouse models genetically ablated of $\mathrm{H}_{2} \mathrm{~S}$ - or polysulfide/ hydropersulfide-producing enzymes $(37,56,79,85)$ and knockdown of these enzymes by siRNA are commonly used, but these techniques require additional expertise and access to specialized facilities $(4,59)$. Although selective inhibitors of $\mathrm{H}_{2} \mathrm{~S}$ - or polysulfide/hydropersulfide-producing enzymes are also useful and indeed are frequently used in biological studies, their selectivity is generally not high, and there is still a need for highly selective inhibitors to investigate the precise functions of $\mathrm{H}_{2} \mathrm{~S}$, hydropersulfide, and polysulfide in living samples $(4,59,81)$.

In this review, we summarize the current status of chemical tools for the study of $\mathrm{H}_{2} \mathrm{~S}$, polysulfide, and hydropersulfide signaling, focusing especially on fluorescent probes and inhibitors, and we also briefly introduce their applications to biological studies.

\section{Development of Fluorescent Probes for $\mathrm{H}_{2} \mathrm{~S}$}

Many fluorescent probes for $\mathrm{H}_{2} \mathrm{~S}$ have been developed based on a variety of reactions, such as the reduction of an azide or nitro moiety to amine, the nucleophilicity of $\mathrm{HS}^{-}$, and the $\mathrm{H}_{2} \mathrm{~S}$-quenching effect of copper (II) ion $\left(\mathrm{Cu}^{2+}\right)$, as summarized hereunder.

\section{Fluorescent probes based on reduction of azide or nitro moiety to amine}

$\mathrm{H}_{2} \mathrm{~S}$ is a reducing reagent and has been used to reduce azides in organic synthesis (69). The sulfide-mediated reduction of aryl azide was recently shown by Henthorn and Pluth to proceed through initial nucleophilic attack of sulfide anion on the electrophilic azide to form an azidethiol intermediate, followed by intramolecular attack of sulfide to generate the amine (31). Since the electron-withdrawing azide is converted to electron-donating amine in this reaction, the electron density of the molecule is greatly changed, and this change can be utilized to modulate the fluorescence of probes.

The first fluorescent probes utilizing azide reduction were SF1 (Fig. 1) and SF2, developed by Chang and colleagues (48). Reduction of the azide group of the xanthene moiety to
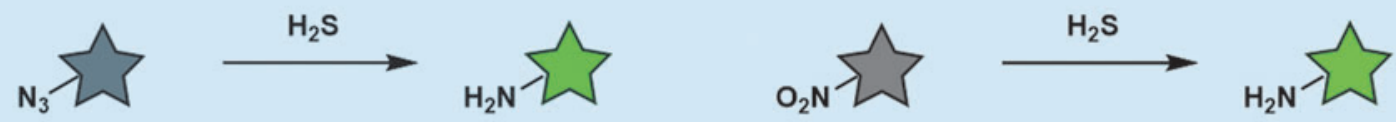<smiles>CC(C)(C)OC(=O)Nc1ccc2c(c1)Oc1cc(N)ccc1C21OC(=O)c2ccccc21</smiles>

SF1<smiles>Nc1ccc2c(c1)Oc1cc(N)ccc1C21OC(=O)c2ccc(C(=O)O)cc21</smiles>

SF5<smiles>Cc1cc(=O)oc2cc([N+]#N)ccc12</smiles>

AzMC<smiles>COCCN1C(=O)c2cccc3c([N+](=O)[O-])ccc(c23)C1=O</smiles>

HSN-1
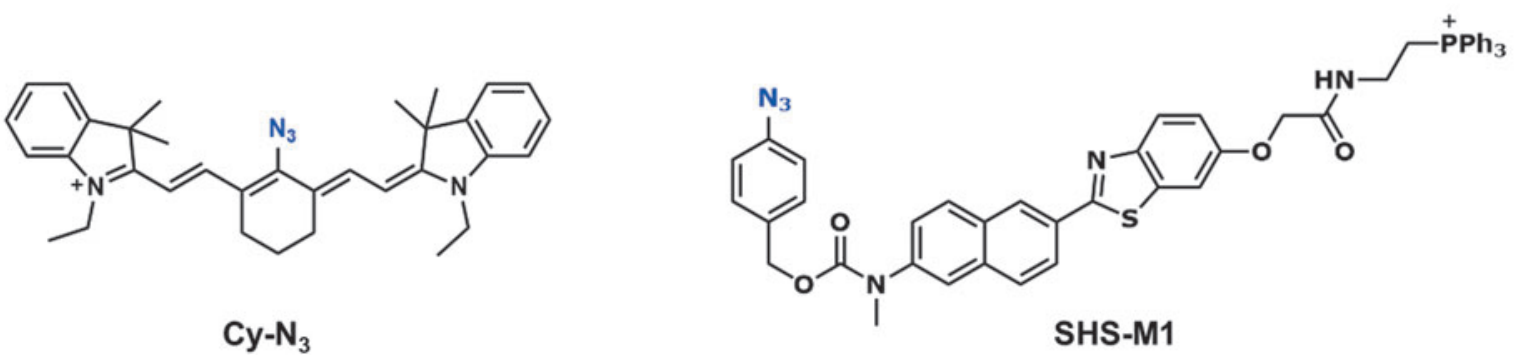

FIG. 1. Fluorescent probes based on reduction of azide or nitro group. Gray or green star indicates nonfluorescent or strongly fluorescent molecule, respectively. 
amine leads to opening of the intramolecular spirocycle of the rhodamine scaffold: this restores the conjugated system of the xanthene moiety, resulting in strong fluorescence emission. The same group subsequently developed several improved probes (SF4-7) based on the same strategy (Fig. 1), using bisazide rhodamines to achieve a lower background signal and an acetoxymethyl group to improve intracellular retention (46).

This azide reduction strategy is broadly applicable to various fluorophores, and various kinds of fluorescent probes for $\mathrm{H}_{2} \mathrm{~S}$ have been developed with different colors or targeting specific organelles, as shown in Figure 1. For example, Barrios and colleagues reported a coumarin-based fluorescent probe, AzMC, which they used for cystathionine $\beta$-synthase (CBS) inhibitor screening (75). Han and colleagues reported a cyanine-based near-infrared (NIR) probe, $\mathrm{Cy}-\mathrm{N}_{3}$ (88). This probe is a colorimetric and ratiometric probe, displaying an emission maximum shift of about $40 \mathrm{~nm}$ upon azide reduction.

$\mathrm{H}_{2} \mathrm{~S}$ fluorescent probes targeting specific organelles have also been developed. For example, Kim and colleagues reported two-photon mitochondria-targeted fluorescent probes, SHS-M1 and SHS-M2, which incorporate a triphenylphosphonium group as a mitochondrial targeting moiety (5). These probes can ratiometrically detect different levels of mitochondrial $\mathrm{H}_{2} \mathrm{~S}$ produced in live cells and living tissues expressing different levels of CBS.

Like the azide group, the nitro group can also be reduced by $\mathrm{H}_{2} \mathrm{~S}$, and Montoya and Pluth utilized this fact to design a fluorescent probe, $\mathrm{HSN}-1$, that incorporates a nitro group into

a
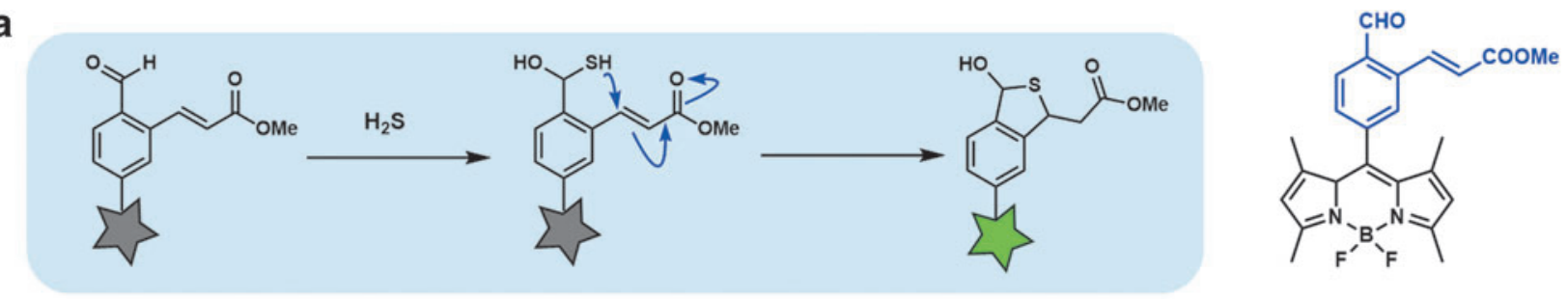

SFP-2

b

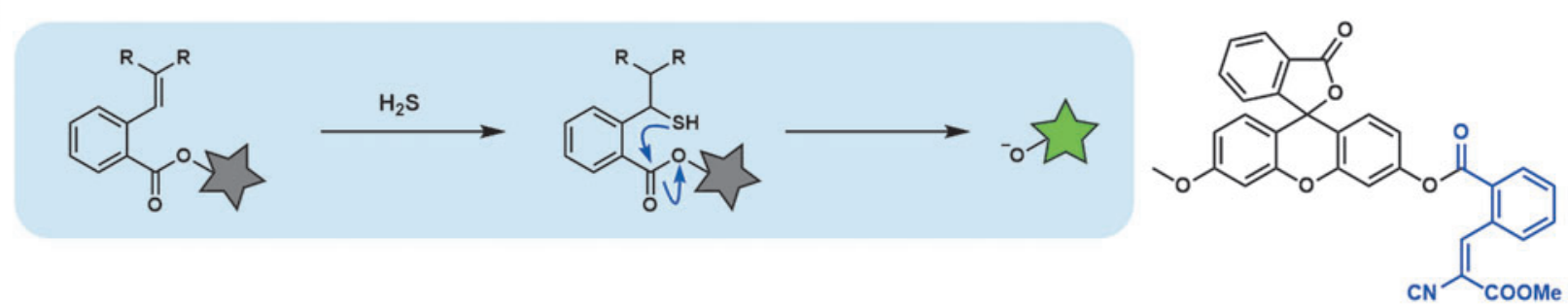

Probe5

C

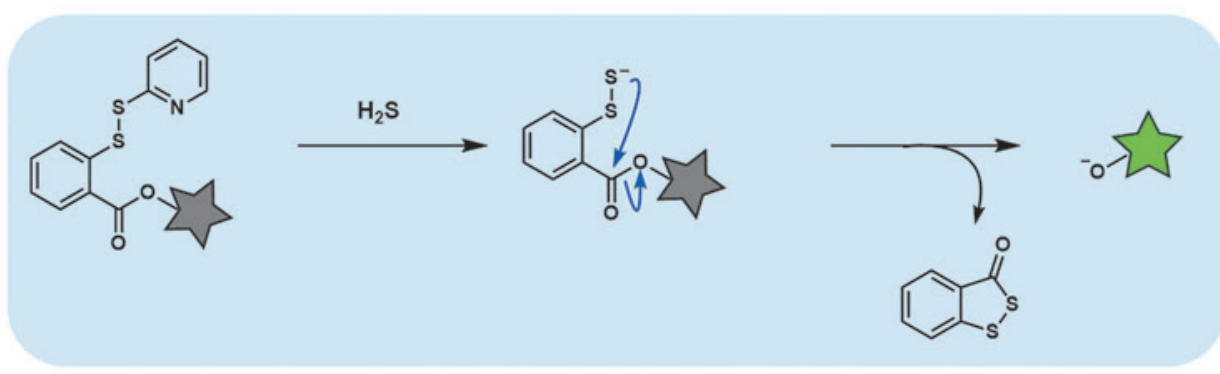<smiles>COc1ccc2c(c1)Oc1cc(OC(=O)c3ccccc3SSc3ccccn3)ccc1C21OC(=O)c2ccccc21</smiles>

WSP1

\section{d}
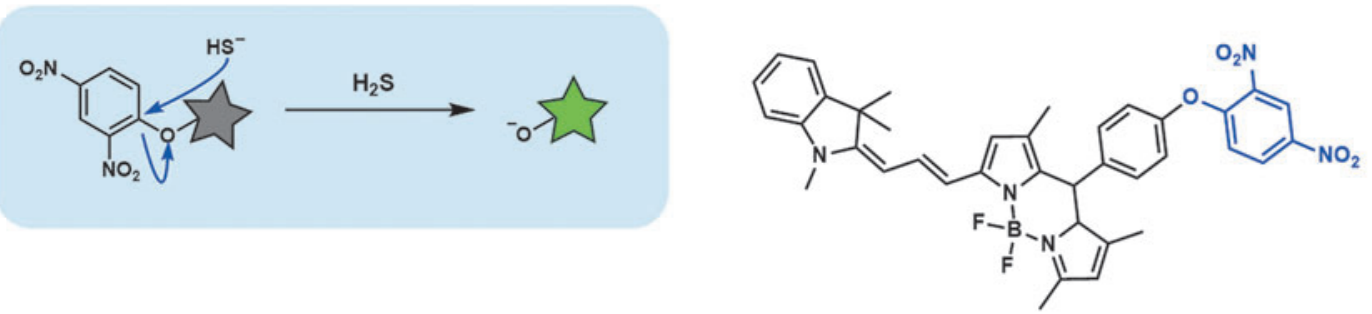

$\mathrm{NIR}-\mathrm{H}_{2} \mathrm{~S}$

FIG. 2. Fluorescent probes based on the nucleophilicity of $\mathbf{H S}^{-}$. (a) Fluorescent probe based on $\mathrm{HS}^{-}$addition to the aldehyde substituent, followed by Michael addition. (b) Fluorescent probe based on a Michael addition strategy to achieve thioacetal cyclization. (c) Fluorescent probe based on disulfide exchange reaction. (d) Fluorescent probe based on nucleophilic addition to the electrophilic moiety of the probe. Gray or green star indicates nonfluorescent or strongly fluorescent molecule, respectively. 
the 1,8-naphthalimide scaffold (54). Thus, several types of $\mathrm{H}_{2} \mathrm{~S}$ fluorescent probes utilizing azide or nitro group reduction have been reported.

\section{Fluorescent probes based on the nucleophilicity of HS}

$\mathrm{H}_{2} \mathrm{~S}$ is highly water soluble and shows $\mathrm{p} K_{\mathrm{a} 1}$ of 7.0 and $\mathrm{p} K_{\mathrm{a} 2}$ of $\sim 12$ (66). So, about two-thirds of $\mathrm{H}_{2} \mathrm{~S}$ is estimated to exist as strongly nucleophilic $\mathrm{HS}^{-}$at physiological $\mathrm{pH}(\mathrm{pH}=7.4)$. Qian et al. utilized this strong nucleophilicity to design fluorescent probes SFP-1 and SFP-2 (Fig. 2a) (64). In these probes, fluorescence off/on switching occurs via $\mathrm{HS}^{-}$addition to the aldehyde substituent, followed by Michael addition of the resulting intermediate to the unsaturated methyl acrylate moiety to form a thiohemiacetal under physiological conditions. The resulting stable tetrahydrothiophene shows strong fluorescence. Xian and colleagues also used a Michael addition strategy to achieve thioacetal cyclization, resulting in ester cleavage, to develop a fluorescent probe (Fig. 2b) (51).

Disulfide exchange reaction by $\mathrm{H}_{2} \mathrm{~S}$ has also been utilized for selective detection of $\mathrm{H}_{2} \mathrm{~S}$. Xian and colleagues reported fluorescein-based fluorescent probes, WSP1-5, in which the disulfide bond is cleaved by $\mathrm{H}_{2} \mathrm{~S}$, followed by intramolecular nucleophilic attack of the persulfide group on the ester moiety (Fig. 2c): this reaction releases the fluorophore, resulting in a large fluorescence increase $(50,62)$. Other similar fluorescent probes, such as a ratiometric probe (83) and a coumarinbased probe (26), have also been reported. Fluorescent probes based on these strategies (Fig. 2a-c) may react with other biothiols such as reduced glutathione (GSH) and Cys, but the resulting intermediates cannot continue to the intramolecular cyclization step, and consequently these probes show high selectivity for $\mathrm{H}_{2} \mathrm{~S}$ over biothiols.

Nucleophilic addition to the electrophilic center of the fluorescent probe has been utilized for the development of ratiometric $\mathrm{H}_{2} \mathrm{~S}$ probes. Guo et al. reported fluorescent probes,
CouMC, based on the selective nucleophilic addition of sulfide anion to coumarin and merocyanine scaffolds (14). Moreover, 2,4-dinitrophenyl (DNP) derivatives were originally employed as masking groups for the phenol group of tyrosine during peptide synthesis, and this protecting group can be removed by thiolytic cleavage (20). Lin and colleagues applied this strategy to remove a highly electron-withdrawing group, DNP, from a probe by reaction with $\mathrm{H}_{2} \mathrm{~S}$, causing the probe to become strongly fluorescent (Fig. 2d) (8).

\section{Fluorescent probes based on the quenching effect of $\mathrm{Cu}^{2+}$}

It is well known that heavy metal ions such as iron (III) ion $\left(\mathrm{Fe}^{3+}\right)$ and $\mathrm{Cu}^{2+}$ quench the fluorescence of a nearby fluorophore. Moreover, based on the hard and soft acids and bases principle (61), sulfide anion has a strong affinity for $\mathrm{Cu}^{2+}$. On this basis, precipitation of $\mathrm{CuS}$ was adapted for $\mathrm{H}_{2} \mathrm{~S}$ detection by incorporating a $\mathrm{Cu}^{2+}$ complex moiety into the fluorophore.

Chang and colleagues reported that a dipicolylaminefluorescein complex with $\mathrm{Cu}^{2+}$ showed a turn-on fluorescence response to $\mathrm{H}_{2} \mathrm{~S}$, but the probe showed no selectivity over other biothiols (16). Our group designed and synthesized a $\mathrm{H}_{2} \mathrm{~S}$ fluorescent probe, hydrogen sulfide imaging probe-1 (HSip-1) (Fig. 3), in which $\mathrm{Cu}^{2+}$ is complexed with an azamacrocyclic ring, cyclen (67). The high stability of this $\mathrm{Cu}^{2+}$ azamacrocyclic complex enabled us to achieve high selectivity for $\mathrm{H}_{2} \mathrm{~S}$ : when $\mathrm{H}_{2} \mathrm{~S}$ binds to the $\mathrm{Cu}^{2+}$ center, the probe shows a large fluorescence enhancement, whereas the azamacrocyclic $\mathrm{Cu}^{2+}$ complex is stable in the presence of other biothiols, such as $10 \mathrm{~m} M$ GSH.

Other probes utilizing this approach, that is, with a $\mathrm{Cu}^{2+}$ complex as a sensing moiety for $\mathrm{H}_{2} \mathrm{~S}$, have been reported based on the combined scaffold of fluorescein and 8-hydroxyquinoline (33) and the phenanthrene-fused dipyrromethene scaffold (65) (Fig. 3).

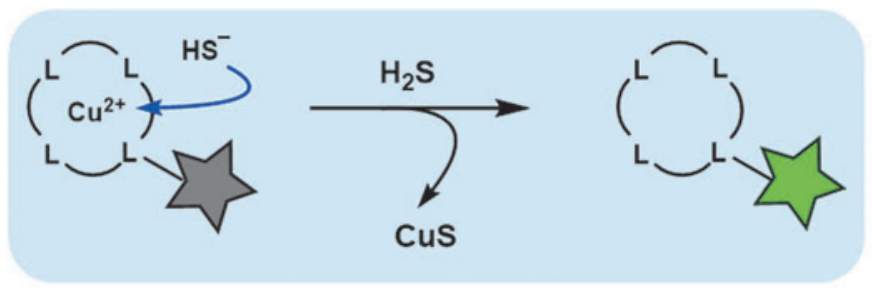

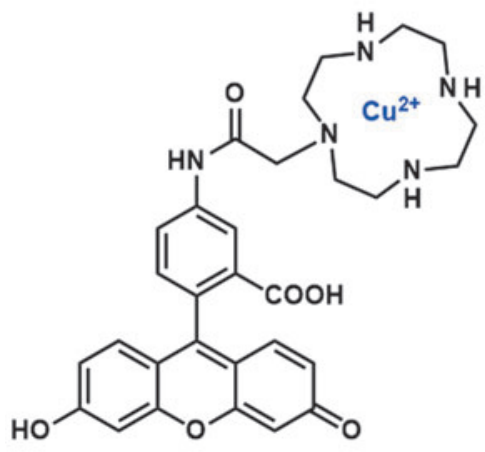

HSip-1<smiles>O=C(COc1cccc2cccnc12)N/N=C/c1cc2oc3cc(=O)ccc-3c(-c3ccccc3C(=O)O)c2cc1O</smiles>

L1Cu

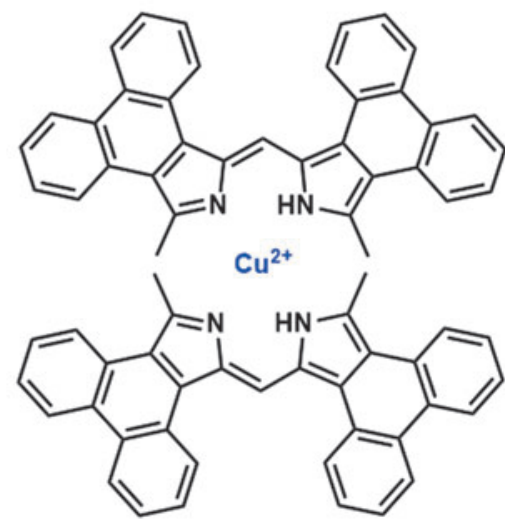

$\mathrm{Cu}-1$

FIG. 3. Fluorescent probes based on precipitation of CuS. Gray or green star indicates nonfluorescent or strongly fluorescent molecule, respectively. 
HSip-1 is also useful to measure $\mathrm{H}_{2} \mathrm{~S}$ production in the course of development of other chemical tools. For example, Nakagawa and colleagues reported photolysis-induced $\mathrm{H}_{2} \mathrm{~S}$ donors utilizing ketoprofenate (22) and xanthone (21) as photolabile protecting groups. They used HSip-1 to evaluate photo-dependent $\mathrm{H}_{2} \mathrm{~S}$ release from these $\mathrm{H}_{2} \mathrm{~S}$ donors. Ichinose and colleagues developed $\mathrm{H}_{2} \mathrm{~S}$-releasing $\mathrm{N}$-methyl-Daspartate receptor (NMDAR) antagonists (combination of NMDAR antagonists with $\mathrm{H}_{2} \mathrm{~S}$ donor) and evaluated changes of cell viability after incubation of cells with these agents (52). They compared the ability of various hybrid $\mathrm{H}_{2} \mathrm{~S}$ donors to increase intracellular $\mathrm{H}_{2} \mathrm{~S}$ by using HSip-1 for $\mathrm{H}_{2} \mathrm{~S}$ detection.

\section{Development of Fluorescent Probes for Hydropersulfide and Polysulfide}

Increasing recognition of the importance of hydropersulfide and polysulfide in biological systems has led to the development of fluorescent probes for sulfane sulfur species; these species consist of sulfur atom(s) with six valence electrons but no charge bound to other sulfur atom(s), as in hydropersulfide and polysulfide. Hydropersulfide has significantly different chemical properties from structurally related thiols $(\mathrm{R}-\mathrm{SH})$. The $\mathrm{p} K_{\mathrm{a}}$ values of hydropersulfides are lower than that of $\mathrm{H}_{2} \mathrm{~S}$ (32), so hydropersulfides should be stronger and more reactive nucleophiles than thiols. In addition, sulfane sulfur is

a

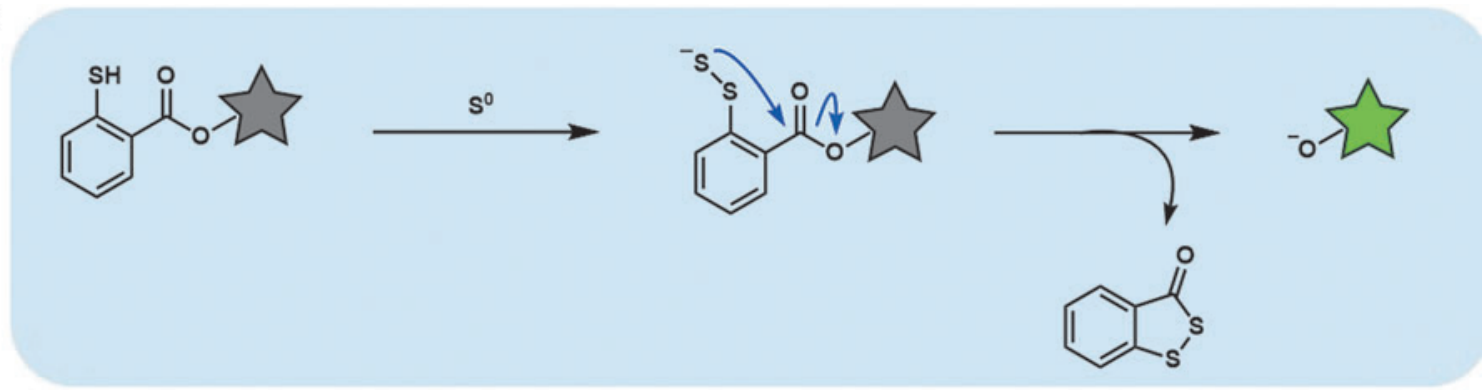<smiles>O=C(Oc1ccc2ccc(=O)oc2c1)c1ccccc1S</smiles>

SSP1

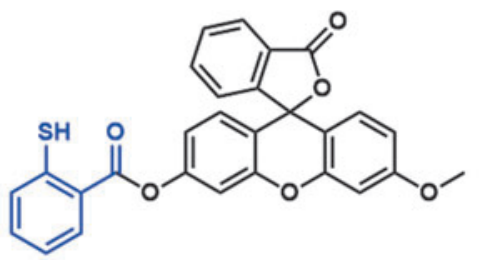

SSP2<smiles>O=C(Oc1ccc2c(c1)Oc1cc(OC(=O)c3ccccc3S)ccc1C21OC(=O)c2ccccc21)c1ccccc1S</smiles>

SSP4

b

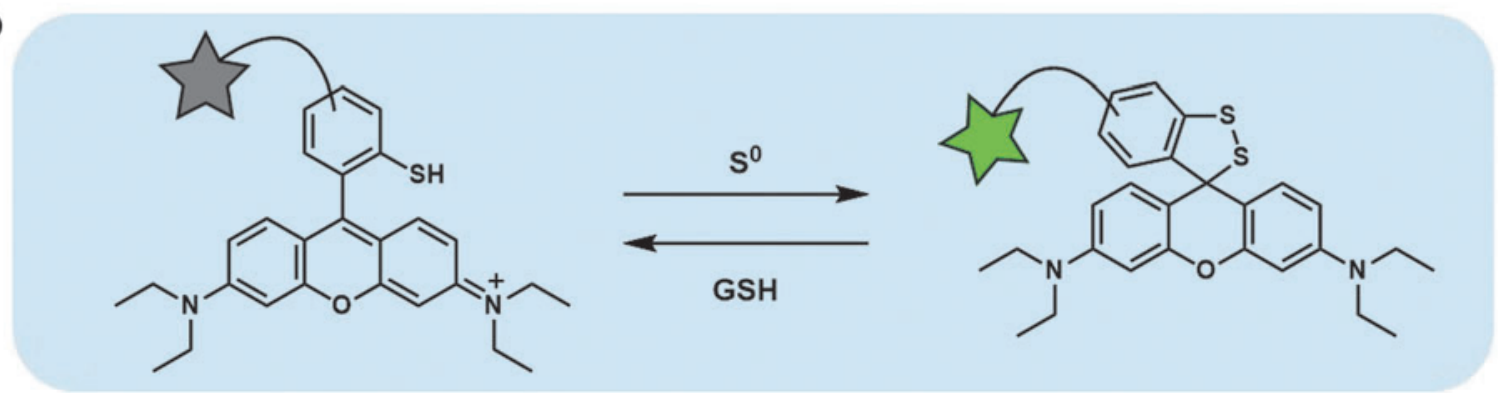<smiles>CCN(CC)c1ccc2c(-c3ccc(C(=O)NC4CCC(NC(=O)c5ccc(-c6c7ccc(=O)cc-7oc7cc(O)ccc67)c(C(=O)O)c5)CC4)cc3S)c3ccc(=[N+](CC)CC)cc-3oc2c1</smiles>

SSip-1

FIG. 4. Fluorescent probes based on sulfane sulfur attachment to thiol. (a) Fluorescent probes for sulfane sulfur, the SSP series. (b) Reversible off/on fluorescent probe for sulfane sulfur, SSip-1. Gray or green star indicates nonfluorescent or strongly fluorescent molecule, respectively. 
electrophilic and can react with nucleophiles. By utilizing these chemical properties, several off/on type fluorescent probes for sulfane sulfur, that is, hydropersulfide and polysulfide, have been designed and developed.

\section{Fluorescent probes based on sulfane sulfur attachment to thiol}

Sulfane sulfur functions as an electrophile and can react with nucleophiles such as thiol group (82). This property was utilized to develop the first fluorescent probes for sulfane sulfur, the SSP series, reported by Xian and colleagues (Fig. 4a) (9). The reaction mechanism for these probes is as follows. First, sulfane sulfur reacts with the sulfur atom of the thiol group of the probe, affording reactive persulfide $\left(\mathrm{R}-\mathrm{SS}^{-}\right)$. Then, intramolecular nucleophilic attack of persulfide $\left(\mathrm{R}-\mathrm{SS}^{-}\right)$on the ester moiety occurs, resulting in strong fluorescence. Thus, the probes can detect sulfane sulfur, including polysulfide and elemental sulfur. Our group also very recently designed and synthesized a reversible off/on fluorescent probe for sulfane sulfur, SSip-1, by utilizing the ability of sulfane sulfur to bind reversibly to other sulfur atoms and the intramolecular spirocyclization reaction of xanthene dyes (Fig. 4b) (73). The fluorescent probe reversibly visualized sulfane sulfur in living A549 cells and primary-cultured hippocampal astrocytes.

\section{Fluorescent probes based on the nucleophilicity of $\mathrm{H}_{2} \mathrm{~S}_{n}$}

Xian and colleagues reported a specific fluorescent probe for hydrogen polysulfides $\left(\mathrm{H}_{2} \mathrm{~S}_{\mathrm{n}}, n>1\right)$, the DSP series (Fig. 5a) (49). In this molecular design, the fluorophore is linked to 2-fluoro-5-nitrobenzoate via an ester bond. Nucleophilic aromatic substitution of hydrogen polysulfide with the fluorine group of the probe affords the persulfide intermediate, and then intramolecular nucleophilic attack of the persulfide $\left(\mathrm{R}-\mathrm{SS}^{-}\right)$on the ester moiety in the probe structure releases the fluorophore. The electron-withdrawing nitro group on the 2-fluoro-5-nitrobenzoate moiety serves to enhance the reactivity of the probe. This approach can also be applied to other fluorophores (Fig. 5a) (23, 24, 28, 35, 70, 89).

For example, Liu and colleagues reported a two-photonexcited fluorescent probe for hydrogen polysulfide, $\mathrm{QS}_{\mathrm{n}}$, using 2-benzothiazol-2-yl-quinolin-6-ol as the two-photon fluorophore and 2-fluoro-5-nitrobenzoate as the $\mathrm{H}_{2} \mathrm{~S}_{n}$ recognition moiety (89). They also reported a ratiometric twophoton fluorescent probe, NRT-HP, utilizing the same $\mathrm{H}_{2} \mathrm{~S}_{\mathrm{n}}$ recognition moiety and quinone methide chemistry (28). They successfully visualized both exogenous and endogenous $\mathrm{H}_{2} \mathrm{~S}_{2} / \mathrm{H}_{2} \mathrm{~S}_{\mathrm{n}}$ in living cells and tissues.

Chen and colleagues developed NIR fluorescent probes, Mito-ss (24) and BD-ss (23), which have aza-BODIPY as the NIR fluorophore and 2-fluoro-5-nitrobenzoate as the polysulfide recognition moiety. Fluorescence of these probes is controlled via donor-excited photoinduced electron transfer because of the strong electron-withdrawing group, that is, the nitro group (78). These probes were utilized for visualization of exogenously added polysulfide, as well as polysulfide endogenously produced via enzymatic reaction in vivo.

Xian and colleagues also developed a $\mathrm{H}_{2} \mathrm{~S}_{\mathrm{n}}$-specific chemosensor based on the nucleophilicity of $\mathrm{H}_{2} \mathrm{~S}_{\mathrm{n}}$ : they discovered a hydrogen polysulfide-mediated aziridine ring- opening reaction, and the developed chemosensor showed high sensitivity and selectivity for $\mathrm{H}_{2} \mathrm{~S}_{\mathrm{n}}$ (12).

Although 2-fluoro-5-nitrobenzoate is utilized as a recognition moiety for hydrogen polysulfide and hydropersulfide in many fluorescent probes, as already mentioned, it can also react with biothiols to form thioether products, leading to undesired consumption of the probes. So, Xian and colleagues developed an improved recognition moiety that reacts only with $\mathrm{H}_{2} \mathrm{~S}_{\mathrm{n}}$ (Fig. 5b) (11). Phenyl 2-(benzoylthio)benzoate showed appropriate selectivity, that is, its thioester bond is labile to polysulfide, but is stable even to biothiols. PSP-3 employed this reaction moiety on a fluorescein scaffold to detect intracellular polysulfide.

A reversible fluorescent probe for hydropersulfide (Fig. 5c) was recently reported by Ojida and colleagues (39). Its reaction mechanism involves nucleophilic reaction of hydropersulfide with the pyronine unit of the probe. The reversible character of this reaction enabled the probe to detect not only increase, but also decrease of hydropersulfide levels in real time. This probe also employed a fluorescence resonance energy transfer (FRET) mechanism as a fluorescence controlling mechanism, which modulates the intramolecular FRET efficiency to induce a dual emission change. Other strategies utilizing the high nucleophilicity of hydrogen polysulfide, such as selenium-sulfur exchange reaction (29) and Michael addition reaction to the cinnamate ester moiety (34), have also been reported.

\section{Fluorescent probe for dual detection}

To understand the mutual relationship and cellular crosstalk between $\mathrm{H}_{2} \mathrm{~S}$ and $\mathrm{H}_{2} \mathrm{~S}_{\mathrm{n}}$, Xian and colleagues developed a single fluorescent probe, DDP-1, that was able to visualize both $\mathrm{H}_{2} \mathrm{~S}$ and $\mathrm{H}_{2} \mathrm{~S}_{\mathrm{n}}$ as different fluorescence signals (Fig. 5d) (10). DDP-1 employs an azide group for $\mathrm{H}_{2} \mathrm{~S}$ detection and phenyl 2-(benzoylthio)benzoate for $\mathrm{H}_{2} \mathrm{~S}_{\mathrm{n}}$ detection.

\section{Development of $\mathrm{H}_{2} \mathrm{~S}$-Producing Enzyme Inhibitors}

Physiological $\mathrm{H}_{2} \mathrm{~S}$ is enzymatically synthesized by CBS, cystathionine $\gamma$-lyase (CSE), and 3-mercaptopyruvate sulfurtransferase (3MST) (59). Among them, CBS and CSE are pyridoxal 5'-phosphate (PLP)-dependent enzymes (Fig. 6a) (4, 63). Several inhibitors of these $\mathrm{H}_{2} \mathrm{~S}$-producing enzymes have been used in biological studies (Fig. 6b).

$\mathrm{D}, \mathrm{L}-\mathrm{Propargylglycine}$ (PAG) and $\beta$-cyano-L-alanine (BCA) are commonly used as inhibitors of CSE: PAG is an irreversible inhibitor of CSE, while BCA is a reversible inhibitor. Both PAG and BCA inhibit CSE in a PLP-dependent manner, and they do not exhibit high selectivity for CSE (4, 59, 81), although their effects on about 140 other PLPdependent enzymes have not been precisely established (59). Also, they have low cell permeability and need to be used at high concentrations (4). Aminooxyacetic acid (AOAA) is commonly used as an inhibitor of CBS (59), but it also blocks CSE. No selective inhibitor of 3MST, which is not a PLPdependent enzyme, has yet been reported (81). Inhibitors of each enzyme are summarized hereunder.

\section{Inhibitors of CSE}

Various $\mathrm{H}_{2} \mathrm{~S}$-generating reactions are catalyzed by CSE, but the main pathway involves $\alpha, \beta$-elimination reaction of 
CHEMICAL TOOLS FOR $\mathrm{H}_{2}$ S AND POLYSULFIDE SIGNALING STUDIES

675

a
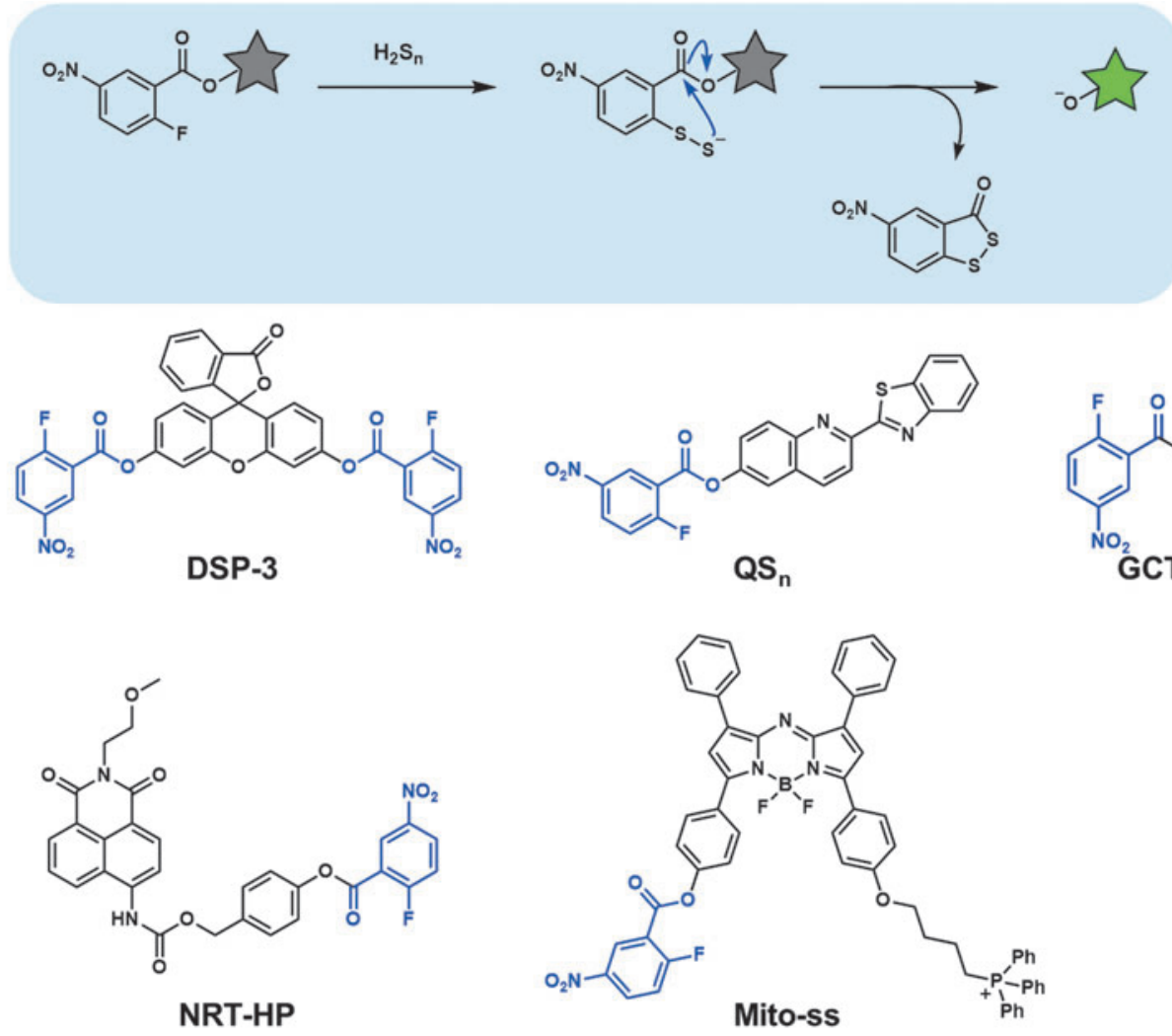

b

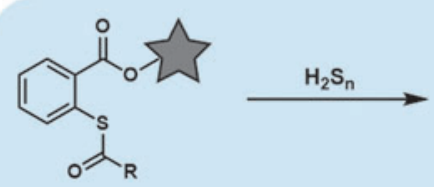

C

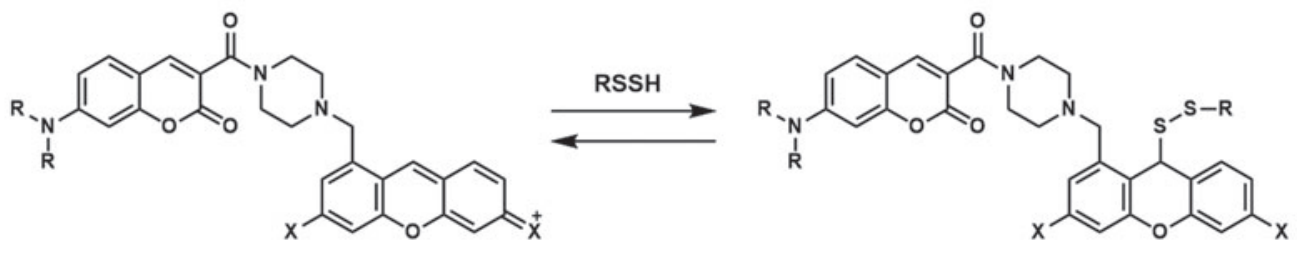

d

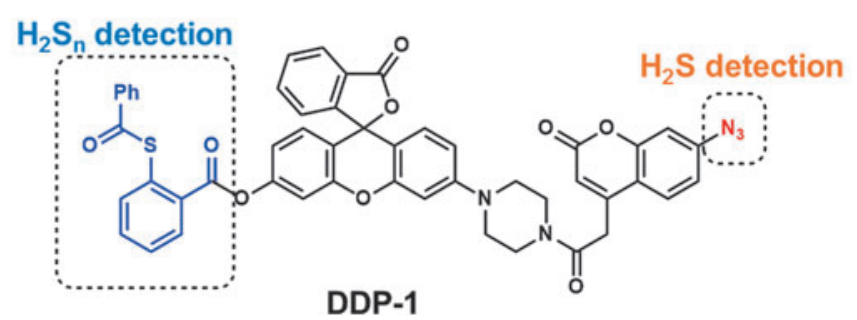

FIG. 5. Fluorescent probes based on the nucleophilicity of $\mathbf{H}_{2} \mathbf{S}_{\mathbf{n}}$. (a) Fluorescent probes based on nucleophilic aromatic substitution of hydrogen polysulfide with the fluorine group of the probe. (b) Highly specific fluorescent probe for hydrogen polysulfide, utilizing phenyl 2-(benzoylthio)benzoate as a recognition moiety. (c) Reversible fluorescent probe for hydropersulfide based on nucleophilic reaction of hydropersulfide with the pyronine unit of the probe. (d) Fluorescent probe for the detection of both $\mathrm{H}_{2} \mathrm{~S}$ and $\mathrm{H}_{2} \mathrm{~S}_{\mathrm{n}}$ as different fluorescence signals. Gray or green star indicates nonfluorescent or strongly fluorescent molecule, respectively. 
<smiles>Cc1ncc(COP(=O)(O)O)c(C=O)c1O</smiles>

PLP<smiles>C#CCC(N)C(=O)O</smiles>

PAG<smiles>N#CCC(N)C(=O)O</smiles>

BCA
$\mathrm{H}_{2} \mathrm{~N}^{-} \mathrm{O}^{\mathrm{COOH}}$

AOAA
FIG. 6. Chemical structure of PLP and inhibitors of $\mathrm{H}_{2} \mathrm{~S}$-generating enzymes. (a) Chemical structure of PLP (63). (b) Chemical structures of inhibitors of $\mathrm{H}_{2} \mathrm{~S}$-generating enzymes. PAG and BCA are inhibitors of CSE, and AOAA is an inhibitor of CBS (4). AOAA, aminooxyacetic acid; BCA, $\beta$-cyano-L-alanine; CBS, cystathionine $\beta$-synthase; CSE, cystathionine $\gamma$-lyase; PAG, D,L-propargylglycine; PLP, pyridoxal 5'-phosphate.
L-Cys, as shown in Figure 7a. The first step of the reaction in CSE is the exchanging reaction from Schiff base between PLP and Lys ${ }^{212}$ of CSE to that between PLP and L-Cys. In this complex, L-Cys is deprotonated and the aromatic ring of PLP is reformed. After that, $\mathrm{SH}^{-}$is released from L-Cys (15).

The reaction mechanism of CSE inhibition by PAG is shown in Figure $7 b$ (72). The first reaction is deprotonation of the $\alpha$-amino group of PAG, and this is followed by transaldimination. The bound PAG is deprotonated by Lys ${ }^{212}$ and an activated allene is formed. The phenoxy group of $\mathrm{Tyr}^{114} \mathrm{nu}-$ cleophilically attacks the allene to deprotonate $\mathrm{Lys}^{212}$, affording a vinyl ether. Finally, transaldimination between Lys $^{212}$ and PAG occurs, but PAG is covalently bound to $\mathrm{Tyr}^{114}$. The bound PAG occupies a space at the substratebinding site of CSE, blocking access of the substrate to the active site so that the enzymatic activity is irreversibly inhibited $(4,81)$.

The inhibition mechanism of BCA appears to be different from that of PAG, because BCA inhibits CSE reversibly $(4,59,81)$. BCA binds to the active site of CSE in a

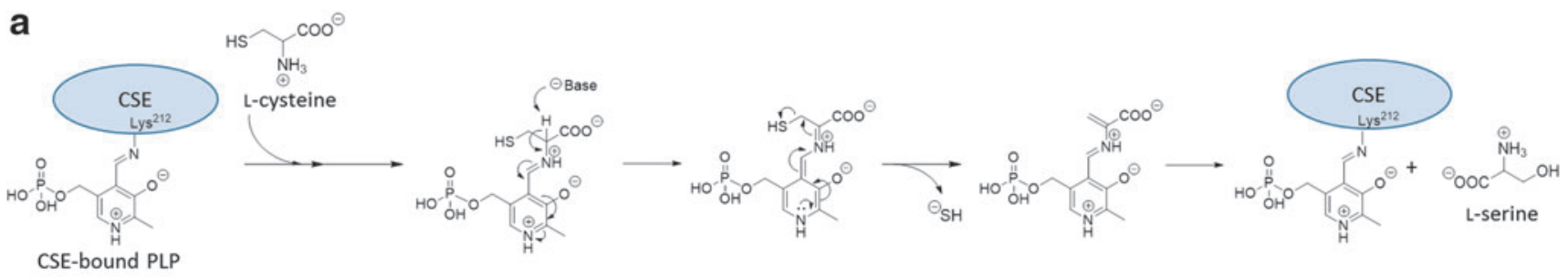

b

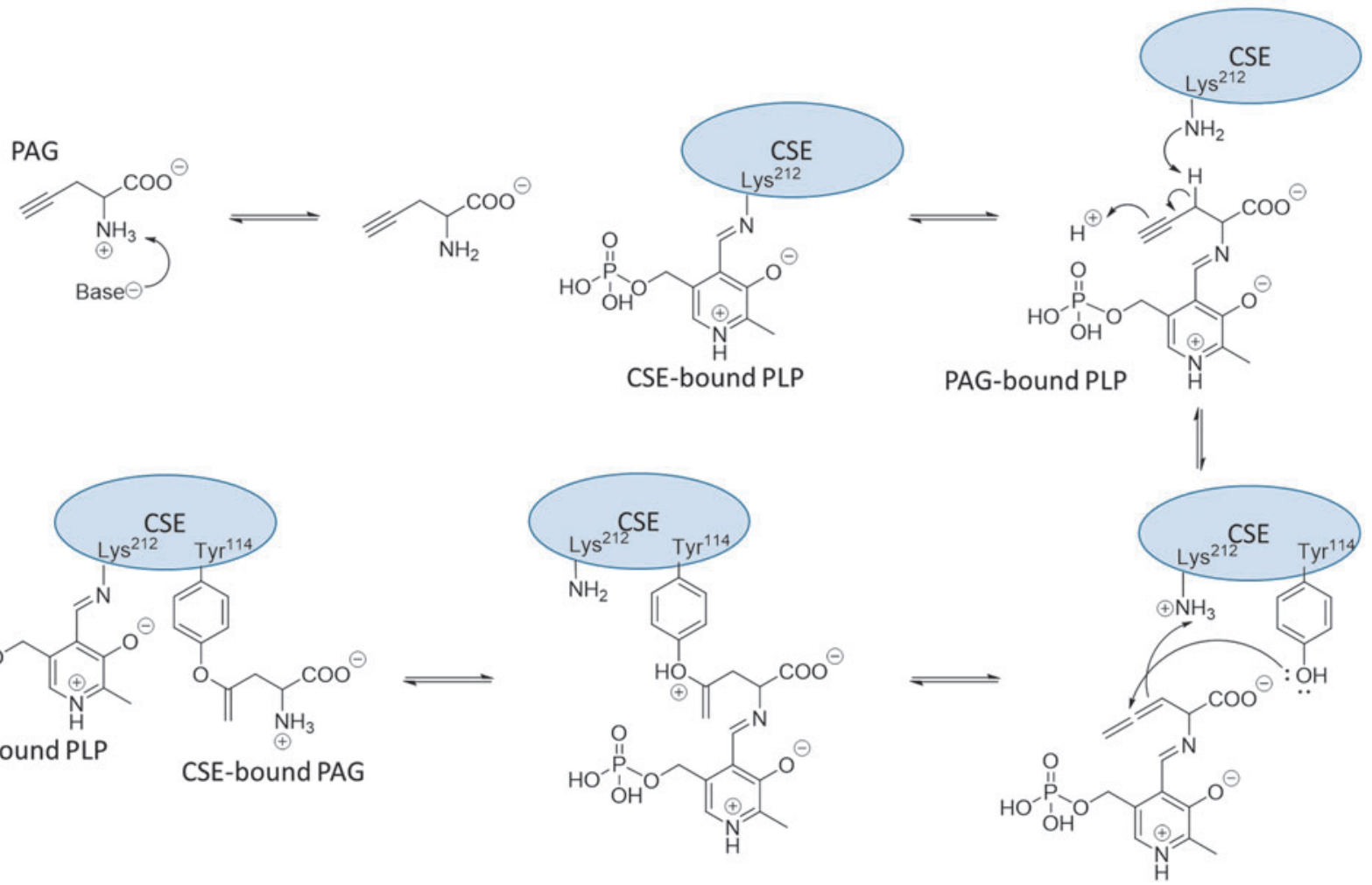

FIG. 7. $\mathrm{H}_{2} \mathrm{~S}$ generation by CSE and mechanism of inhibition of CSE by PAG. (a) Mechanism of $\mathrm{H}_{2} \mathrm{~S}$ generation by CSE: L-Cysteine acts as a substrate and undergoes $\alpha, \beta$ elimination to generate $\mathrm{L}$-serine with release of $\mathrm{SH}^{-}$(15). (b) Mechanism of inhibition of CSE by PAG (72). 
FIG. 8. Mechanism of $\mathrm{H}_{2} \mathrm{~S}$ generation by CBS $(14,15)$.
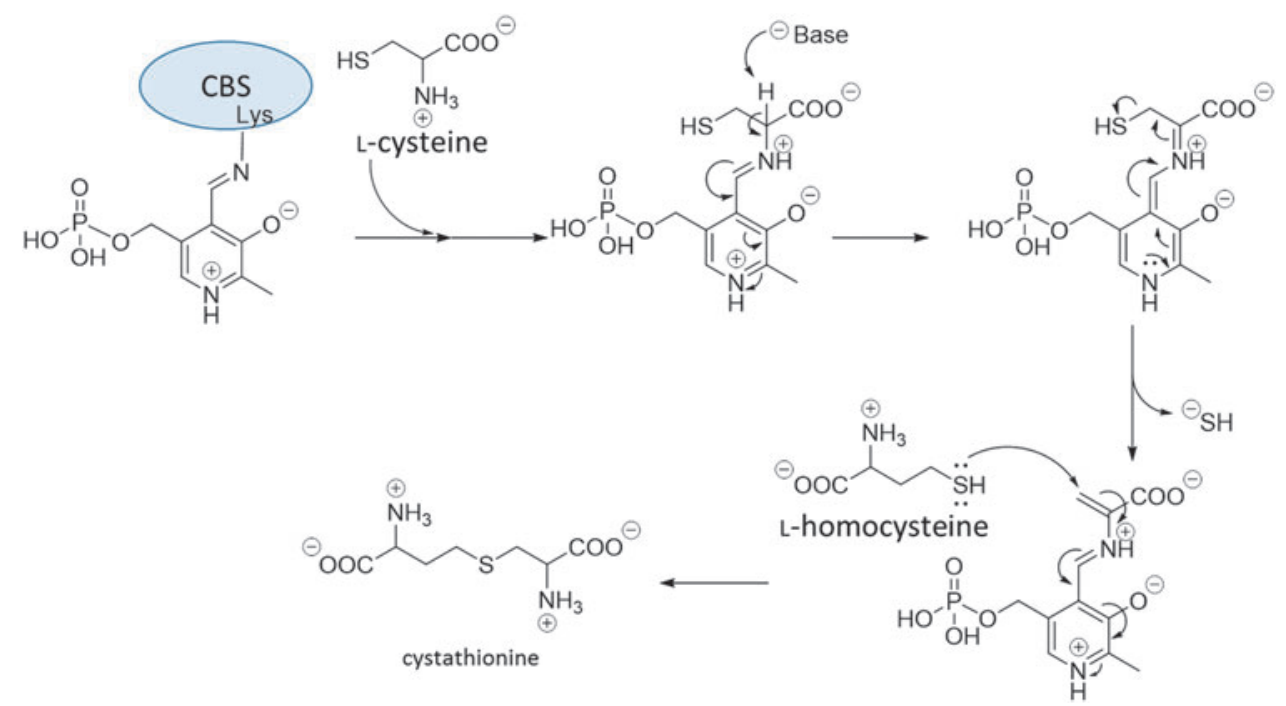

PLP-dependent manner, probably forming a Schiff base linkage, but this linkage can be hydrolyzed, which may account for the reversibility of this inhibition (2).

\section{Inhibitors of CBS}

$\beta$-Replacement of L-Cys by L-homocysteine is the main route of $\mathrm{H}_{2} \mathrm{~S}$ generation catalyzed by CBS (Fig. 8) (13). The first half of the reaction is similar to the reaction of CSE with L-Cys, that is, L-Cys and PLP form a Schiff base linkage and L-Cys is deprotonated. When PLP reforms its aromatic ring, $\mathrm{HS}^{-}$is released and the olefin in L-Cys is formed. Then, $\mathrm{L}-$ homocysteine attacks the olefin moiety, affording cystathionine (Fig. 8). AOAA has also been used as an inhibitor of CBS $(4,59,81)$. Inhibition by AOAA is thought to be because of the formation of the Schiff base between AOAA and PLP at the active site of CBS, because it has been reported that AOAA forms a Schiff base linkage with PLP in CSE to block the generation of $\mathrm{H}_{2} \mathrm{~S}$ (6). AOAA also inhibits other PLPdependent enzymes, showing relatively low selectivity for CBS (4).

\section{Inhibitors of 3MST}

3MST generates $\mathrm{H}_{2} \mathrm{~S}$ from 3-mercaptopyrvate (3MP) in the presence of dithiols, such as thioredoxin (Trx) or dihydrolipoic acid (DHLA) (Fig. 9) (53). 3MP is generated from
L-Cys and $\alpha$-oxoglutarate $(\alpha-K G)$, catalyzed by cysteine aminotransferase. The Cys residue at the active site of 3MST attacks the thiol group of $3 \mathrm{MP}$, forming the persulfide at the active site $\mathrm{Cys}^{247}$. The persulfide is then attacked by one thiol of dithiol (Trx or DHLA), and the dithiol forms the persulfide group. The transferred persulfide is attacked by the other thiol of the dithiol, producing $\mathrm{SH}^{-}$. No selective inhibitor of 3MST has been reported so far, although pyruvate, menadione, 3mercaptopropionic acid, and 3-chloropyruvate are nonselective inhibitors of 3MST (81).

\section{Recent reports of selective inhibitors}

Thorson et al. (75) screened a structurally diverse library of 1900 chemical compounds with a wide range of biological activities for inhibitors of CBS by using AzMC as a fluorescence probe for $\mathrm{H}_{2} \mathrm{~S}$ (Fig. 1), and found 12 hit compounds in the initial screening. After considering their selectivity for CBS and excluding compounds directly reacting with $\mathrm{H}_{2} \mathrm{~S}$, 1,4-naphthoquinone and tangeritin were concluded to be selective inhibitors of CBS; these compounds showed selectivity for CBS over CSE (Fig. 10a).

Cirino and colleagues (7) reported that D-penicillamine (Dpen), which has a structure similar to Cys and is used as an antirheumatic drug, acts as a selective inhibitor of CSE in a PLP-dependent manner (Fig. 10b). First, they showed that

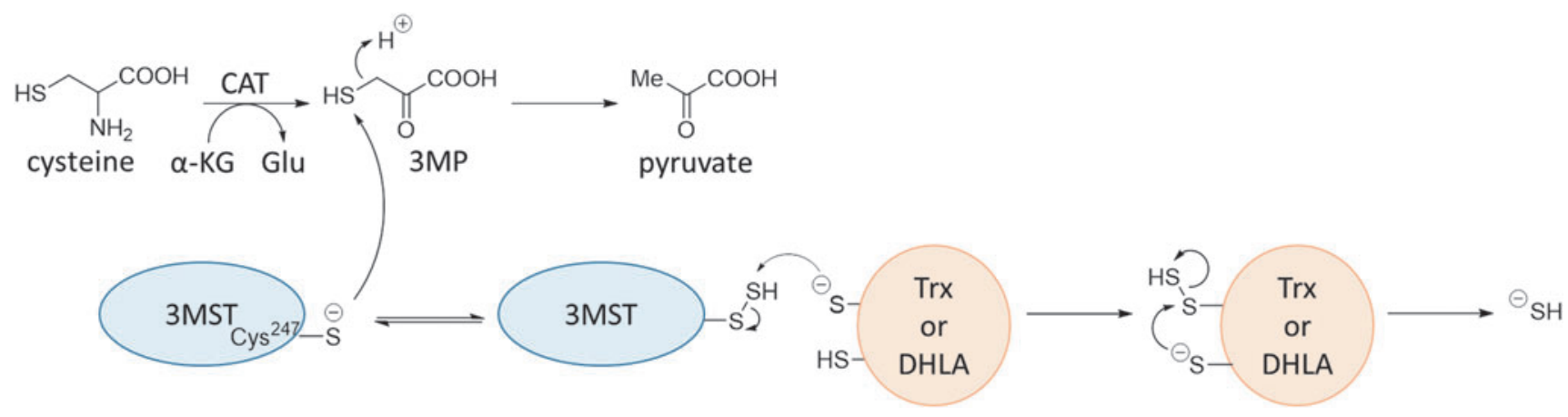

FIG. 9. Mechanism of $\mathrm{H}_{2} \mathrm{~S}$ generation by 3MST (53). 3MST, 3-mercaptopyruvate sulfurtransferase. 
a hit compound

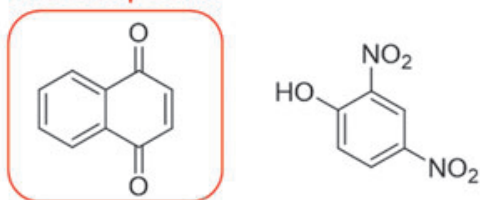<smiles>COc1ccc2c(c1)OC1(O)COc3cc(OC)c(OC)cc3C1=C2</smiles><smiles>O=C(/C=C/C=C/c1ccc2c(c1)OCO2)N1CCCCC1</smiles>

1,4-naphthoquinone<smiles>COc1c(O)cc2oc3cc(O)c(CC=C(C)C)c(O)c3c(=O)c2c1C(C)C=C(C)C</smiles><smiles>O=c1cc(-c2ccc(O)cc2)oc2cc(O)cc(O)c12</smiles><smiles>N=C(N)NC(=O)c1nc(Cl)c(N)nc1N</smiles><smiles>O=[N+]([O-])c1cc(O)c(O)c([N+](=O)[O-])c1</smiles>

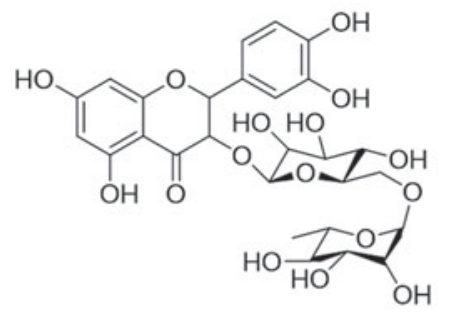<smiles>COc1cc2ccc(=O)oc2c(O)c1O</smiles><smiles>CCOc1ccc(-c2cc(=O)c3c(OC)c(OC)c(OC)c(OCC)c3o2)cc1</smiles><smiles>NC(CO)C(=O)NNCc1ccc(O)c(O)c1O</smiles>

b<smiles>CC(C)(S)[C@H](N)C(=O)O</smiles><smiles>C#CCNC(=O)[C@@H]1CSCN1</smiles>

$1 a$

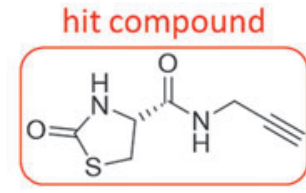

$2 a$<smiles>C#CCNC(=O)[C@H](N)Cc1cccs1</smiles>

$3 a$<smiles>C#CCOc1ccc(N)cc1C(=O)O</smiles>

$4 a$

FIG. 10. Recently reported inhibitors of CSE and CBS. (a) Twelve hit compounds in the initial screening of CBS inhibitors by Thorson et al. 1,4-Naphthoquinone and tangeritin were reported to specifically inhibit $\mathrm{H}_{2} \mathrm{~S}$ production by $\mathrm{CBS}$ (75). (b) Chemical structures of L-cysteine and D-pencillamine (7). (c) Chemical structures of compounds synthesized by Corvino et al. (17) as candidate inhibitors of CSE. All of them have a propargyl group. Compounds (1a) and (2a) are cysteine derivatives, and also have a thiazolidine moiety. Compounds (3a) and (4a) have an aromatic group that is expected to interact with CSE (17).

D-pen is not metabolized by CSE in vitro. Cell-free assay with recombinant $\mathrm{CSE}$ showed that D-pen reduced $\mathrm{H}_{2} \mathrm{~S}$ synthesis, and was about 30 times more selective for CSE than CBS. Then, they showed that D-pen inhibits CSE by interacting with PLP, and they confirmed that it inhibits CSE in vivo. Thus, D-pen should be a useful scaffold for the design of novel selective inhibitors for CSE.

Structure-based and fragment-based approaches to find CSE inhibitors have been reported by Pastore and colleagues (17). They discovered that Cys derivatives with a propargyl group in the $\alpha$-carboxyl position selectively inhibit CSE (Fig. 10c). They synthesized four new compounds, all having a propargyl group; this is an essential structural element for inhibition of CSE by PAG. Two of them have structure similar to Cys, whereas the other two contain an aromatic group, which is expected to interact with the amino acid residue of CSE at the active site. When pharmacological assays were performed, compound 2 a (Fig. 10c) showed good water solubility, suggesting that it might be practically useful as an inhibitor. Compound $2 \mathrm{a}$ also showed high selectivity for CSE against CBS. They also reported that the inhibitory activity of compound $2 \mathrm{a}$ was greater than that of PAG.

Our group very recently reported a first 3MST-selective inhibitor (30). We performed high-throughput screening for 3MST inhibitors in a chemical library containing 174,118 compounds by using our selective fluorescent probe for $\mathrm{H}_{2} \mathrm{~S}$, HSip-1 (Fig. 3). In the assay, purified 3MST and the substrate 3-MP were used and HSip-1 reacted with $\mathrm{H}_{2} \mathrm{~S}$ released by the enzymatic reaction. Compounds that suppressed the fluorescence increase of HSip-1 in response to $\mathrm{H}_{2} \mathrm{~S}$ were selected, and we discovered several selective inhibitors of 3MST. 


\section{Cellular Applications of Fluorescent Probes and Inhibitors in Biological Studies}

Although there is great interest in the biological roles of $\mathrm{H}_{2} \mathrm{~S}$, hydropersulfide, and polysulfide, many of the underlying molecular events remain poorly understood. Therefore, fluorescent probes for these sulfur molecules and inhibitors for related enzymes are needed to enable detailed studies of their molecular mechanisms. In some cases, both fluorescent probes and selective inhibitors have been used.

\section{Investigation of intracellular endogenous $\mathrm{H}_{2} \mathrm{~S}$}

$\mathrm{Li}$ and colleagues have developed a mitochondria-targeted fluorescent probe for $\mathrm{H}_{2} \mathrm{~S}$ (58). When HeLa cells were preincubated with $1 \mathrm{~m} M$ PAG for $1 \mathrm{~h}$ and then incubated with their fluorescent probe $(10 \mu M)$ for $30 \mathrm{~min}$, the fluorescence intensity was clearly decreased, and this fluorescence decrease was considered to reflect the intracellular basal level of $\mathrm{H}_{2} \mathrm{~S}$.

Chang and colleagues have reported real-time visualization of endogenous $\mathrm{H}_{2} \mathrm{~S}$ produced in live human umbilical vein endothelial cells (HUVECs) upon stimulation with vascular endothelial growth factor (VEGF), using a new fluorescent probe for $\mathrm{H}_{2} \mathrm{~S}$ (46). CSE was identified as the key $\mathrm{H}_{2} \mathrm{~S}$-producing enzyme in the vasculature, and treatment of HUVECs with PAG attenuated the fluorescence signal of the probe. This indicates that CSE contributes to the observed $\mathrm{H}_{2} \mathrm{~S}$ generation. They also reported that not only CSE but also CBS was expressed in HUVECs, so it is possible that CBS also has a role in this biological system.

$\mathrm{Yi}$ et al. reported a dual-response fluorescent probe for detecting $\mathrm{H}_{2} \mathrm{O}_{2}$ and $\mathrm{H}_{2} \mathrm{~S}$ (86). When $200 \mu M \mathrm{GSH}$ was added to HEK293 cells in the presence of their fluorescent probe, marked fluorescence enhancement was observed, representing endogenous $\mathrm{H}_{2} \mathrm{~S}$. In contrast, when HEK293 cells were coincubated with phorbol-12-myristate-13-acetate (PMA; an inducer of endogenous $\mathrm{H}_{2} \mathrm{O}_{2}$ production) and the probe, a marked fluorescence increase was observed, representing endogenous $\mathrm{H}_{2} \mathrm{~S}$ production induced by endogenous $\mathrm{H}_{2} \mathrm{O}_{2}$ in living cells. The PMA-induced fluorescence increase was decreased by addition of PAG, implying that PAG may inhibit PMA-induced $\mathrm{H}_{2} \mathrm{~S}$ biogenesis.

Dufton et al. investigated the regulation of leukocyte $\mathrm{H}_{2} \mathrm{~S}$ synthesis by using a fluorescent probe for $\mathrm{H}_{2} \mathrm{~S}$, SF5 (Fig. 1) (18). To assess $\mathrm{H}_{2} \mathrm{~S}$ synthesis in primary murine cells, they used P-Gel-derived macrophages, and they observed an increase of SF5 fluorescence in the living cells. Addition of LCys and PLP to the culture medium for $1 \mathrm{~h}$ had no effect on intracellular $\mathrm{H}_{2} \mathrm{~S}$ generation, whereas the inhibition of CSE and CBS with L-PAG and AOAA significantly reduced $\mathrm{H}_{2} \mathrm{~S}$ synthesis in a concentration-dependent manner.

$\mathrm{Yi}$ and colleagues have reported FRET-based ratiometric probes for $\mathrm{H}_{2} \mathrm{~S}$ (80). Fluorescence imaging with these probes indicated that $\mathrm{D}$-Cys induces greater $\mathrm{H}_{2} \mathrm{~S}$ production than does L-Cys in mitochondria of HEK293 cells. PAG also inhibited Cys-dependent endogenous $\mathrm{H}_{2} \mathrm{~S}$ production in a chiral-sensitive manner in living cells, that is, D-PAG inhibited D-Cys-dependent $\mathrm{H}_{2} \mathrm{~S}$ production more efficiently than L-PAG, whereas L-PAG inhibited L-Cys-dependent $\mathrm{H}_{2} \mathrm{~S}$ production more efficiently than D-PAG.

Pluth and colleagues have reported a fluorescent probe for detecting endogenously produced $\mathrm{H}_{2} \mathrm{~S}$ in $\mathrm{C} 6$ rat glial cells, which express CBS (27). They measured the fluorescence response in cells that had been pretreated with AOAA $(20 \mu M)$, and observed a significant reduction compared with untreated cells, presumably reflecting endogenous enzymatic production of $\mathrm{H}_{2} \mathrm{~S}$.

\section{Investigation of intracellular endogenous hydropersulfide and polysulfide}

Chen and colleagues have reported a fluorescent probe for mitochondrial hydrogen polysulfides, Mito-ss (Fig. 5a) (24). They tried to detect endogenously produced hydrogen polysulfides by perturbing the pool of hydrogen polysulfides in RAW264.7 cells. RAW264.7 cells were stimulated with lipopolysaccharide (LPS, $1 \mu \mathrm{g} / \mathrm{m} M$ ) for $16 \mathrm{~h}$ and then incubated with Mito-ss for $15 \mathrm{~min}$. LPS induces CSE mRNA overexpression, which resulted in an increase of hydrogen polysulfide production. The cells showed a dramatic increase in intracellular fluorescence intensity, suggesting that the probe could detect endogenously produced hydrogen polysulfides.

They also pretreated the cells with PAG $(100 \mu M)$ for $10 \mathrm{~min}$ and then stimulated them with LPS for $16 \mathrm{~h}$ and incubated them with Mito-ss for another $15 \mathrm{~min}$. In this case, the fluorescence response was attenuated, indicating that CSE contributes to the observed hydrogen polysulfide generation.

$\mathrm{Yu}$ and colleagues have reported a fluorescent probe for both superoxide anion and hydrogen polysulfides in mitochondria, Hcy-Mito (35). When HUVECs were incubated with $1 \mu M$ Hcy-Mito for $15 \mathrm{~min}$, the cells did not show any significant fluorescence increase, and the apoptosis rate was almost $0 \%$. But, when the cells were treated with VEGF $40 \mathrm{ng} / \mathrm{ml}$ for $15 \mathrm{~min}$ to trigger a superoxide anion burst and then incubated for $30 \mathrm{~min}$, they showed strong fluorescence, indicating increased production of hydrogen polysulfides. Moreover, when the cells were preincubated with $100 \mu M$ PAG for $10 \mathrm{~min}$ to inhibit CSE, the rate of apoptosis increased to $20.9 \%$. This result indicates that the main antioxidant activity in HUVECs was caused by hydrogen polysulfides.

The same group has also reported a ratiometric fluorescent probe for Cys hydropersulfide, Cy-Dise (29). When HL-7702 cells were pretreated with $N$-ethylmaleimide to deplete endogenous Cys hydropersulfides, almost no increase of the ratiometric fluorescence signal was detected with $\mathrm{Cy}$-Dise. Pretreatment of the cells with PAG also gave a low ratiometric response, indicating a low level of Cys hydropersulfide. However, CSE-overexpressing cells showed a strong ratiometric increase, indicating a high level of Cys hydropersulfide in the cells. CSE-overexpressing cells were also treated with hydroxylamine to inhibit CSE activity, and in this case, the ratiometric signal showed a low level of Cys hydropersulfide.

In contrast, pretreatment with $100 \mu M$ cystine for $1 \mathrm{~h}$ increased the level of Cys hydropersulfide. When the cells were treated with $100 \mu M$ sulfasalazine for $3 \mathrm{~h}$, they showed a low level of Cys hydropersulfide, presumably because sulfasalazine inhibits Cys/glutamine transporter, which is one of the transporters of cystine. Thus, the intracellular level of Cys hydropersulfide can be changed by exogenous stimuli.

Ojida and colleagues have reported a reversible ratiometric fluorescent probe for hydropersulfides (Fig. 5c) (39). When A549 cells were treated with the fluorescent probe for $20 \mathrm{~min}$, 
bright fluorescence was observed in the cytosolic region. When A549 cells were preincubated with the probe, and then treated with cystine, a gradual increase of the hydropersulfide level was observed. This increase was suppressed by treatment with AOAA. Conversely, treatment of the cells with auranofin, an inhibitor of thioredoxin reductase (TrxR), induced an increase in the intracellular hydropersulfide level.

Moreover, when fluorescence imaging of live A549 cells treated with L-Cys was performed using the fluorescent probe, the level of hydropersulfide increased in a timedependent manner. Treatment of the cells with AOAA effectively suppressed the increase of hydropersulfide level induced by L-Cys. Unlike the case of the cystine experiment, inhibition of TrxR by auranofin did not cause an increase of the hydropersulfide level, implying that direct conversion of $\mathrm{L}-\mathrm{Cys}$ to Cys hydropersulfide is not a major pathway of hydropersulfide formation in living cells.

\section{Conclusions}

Here, we have reviewed fluorescent probes for $\mathrm{RSS}\left(\mathrm{H}_{2} \mathrm{~S}\right.$, hydropersulfide, and polysulfide) based on a variety of design strategies, together with inhibitors of CSE, CBS, and 3MST, and we have introduced their biological applications. It is well established that $\mathrm{H}_{2} \mathrm{~S}$ acts as a signaling and effector molecule, but so far its chemical mechanisms of action remain largely unknown.

In contrast, biological studies with recently developed fluorescent probes and detection methods for $\mathrm{H}_{2} \mathrm{~S}$, hydropersulfide, and polysulfide have suggested that hydropersulfide and polysulfide may be the actual signaling molecules mediating some of the physiological functions of $\mathrm{H}_{2} \mathrm{~S}$. Inhibitors of enzymes that synthesize these RSS are also powerful reagents for biological studies, but the selectivity and affinity of available small-molecular inhibitors are still insufficient and there are some conflicting results in the literature. Incorrect usage of inhibitors or failure to recognize pharmacologically relevant off targets would likely generate misleading results $(3,68)$, and detailed investigation of the specificity of various inhibitors seems to be needed for the high-quality biological research.

Further development and application of chemical tools for $\mathrm{H}_{2} \mathrm{~S}$, hydropersulfide, and polysulfide studies, especially tools able to detect and regulate the endogenous levels of these reactive sulfur molecules in cellulo, are expected to lead to an improved understanding of the role of these mediators in the control mechanisms of multiple physiological functions.

\section{Acknowledgments}

This work was supported, in part, by grants by JSPS KAKENHI Grant Numbers $16 \mathrm{H} 00823$ and $16 \mathrm{H} 05099$ to K.H., and SENTAN, JST to K.H., who was also supported by Mochida Memorial Foundation for Medical and Pharmaceutical Research.

\section{References}

1. Abe $\mathrm{K}$ and Kimura $\mathrm{H}$. The possible role of hydrogen sulfide as an endogenous neuromodulator. J Neurosci 16: 10661071, 1996.

2. Alston TA, Porter DJT, Mela L, and Bright HJ. Inactivation of alanine aminotransferase by the neurotoxin $\beta$-cyano-Lalanine. Biochem Biophys Res Commun 92: 299-304, 1980.
3. Arrowsmith $\mathrm{CH}$, Audia, JE, Austin $\mathrm{C}$, Baell J, Bennett J, Blagg J, Bountra C, Brennan PE, Brown PJ, Bunnage ME, Buser-Doepner C, Campbell RM, Carter AJ, Cohen P, Copeland RA, Cravatt B, Dahlin JL, Dhanak D, Edwards AM, Frederiksen M, Frye SV, Gray N, Grimshaw CE, Hepworth D, Howe T, Huber KVM, Jin J, Knapp S, Kotz JD, Kruger RG, Lowe D, Mader MM, Marsden B, Mueller-Fahrnow A, Müller S, O'Hagan RC, Overington JP, Owen DR, Rosenberg SH, Ross R, Roth B, Schapira M, Schreiber SL, Shoichet B, Sundström M, Superti-Furga G, Taunton J, Toledo-Sherman L, Walpole C, Walters MA, Willson TM, Workman P, Young RN, and Zuercher WJ. The promise and peril of chemical probes. Nat Chem Biol 11: 536-541, 2015.

4. Asimakopoulou A, Panopoulos P, Chasapis CT, Coletta C, Zhou Z, Cirino G, Giannis A, Szabo C, Spyroulias GA, and Papapetropoulos A. Selectivity of commonly used pharmacological inhibitors for cystathionine $\beta$ synthase (CBS) and cystathionine $\gamma$ lyase (CSE). Br J Pharmacol 169: 922932, 2013.

5. Bae SK, Heo CH, Choi DJ, Sen D, Joe EH, Cho BR, and Kim HM. A ratiometric two-photon fluorescent probe reveals reduction in mitochondrial $\mathrm{H} 2 \mathrm{~S}$ production in Parkinson's disease gene knockout astrocytes. J Am Chem Soc 135: 9915-9923, 2013.

6. Beeler $\mathrm{T}$ and Churchich JE. Reactivity of the phosphopyridoxal group of cystathionase. J Biol Chem 251: 52675271, 1976.

7. Brancaleone V, Esposito I, Gargiulo A, Vellecco V, Asimakopoulou A, Citi V, Calderone V, Gobbetti T, Perretti M, Papapetropoulos A, Bucci M, and Cirino G. DPenicillamine modulates hydrogen sulfide $\left(\mathrm{H}_{2} \mathrm{~S}\right)$ pathway through selective inhibition of cystathionine- $\gamma$-lyase. $\mathrm{Br} J$ Pharmacol 173: 1556-1565, 2016.

8. Cao XW, Lin WY, Zheng KB, and He LW. A near-infrared fluorescent turn-on probe for fluorescence imaging of hydrogen sulfide in living cells based on thiolysis of dinitrophenyl ether. Chem Commun 48: 10529-10531, 2012.

9. Chen W, Liu CR, Peng B, Zhao Y, Pacheco A, and Xian M. New fluorescent probes for sulfane sulfurs and the application in bioimaging. Chem Sci 4: 2892-2896, 2013.

10. Chen W, Pacheco A, Takano Y, Day JJ, Hanaoka K, and Xian M. A single fluorescent probe to visualize hydrogen sulfide and hydrogen polysulfides with different fluorescence signals. Angew Chem Int Ed 55: 9993-9996, 2016.

11. Chen W, Rosser EW, Matsunaga T, Pacheco A, Akaike T, and Xian M. The development of fluorescent probes for visualizing intracellular hydrogen polysulfides. Angew Chem Int Ed 54: 13961-13965, 2015.

12. Chen W, Rosser EW, Zhang D, Shi W, Li Y, Dong WJ, Ma $\mathrm{H}, \mathrm{Hu} \mathrm{D}$, and Xian M. A specific nucleophilic ring-opening reaction of aziridines as a unique platform for the construction of hydrogen polysulfides sensors. Org Lett 17: 2776-2779, 2015.

13. Chen X, Jhee $\mathrm{KH}$, and Kruger WD. Production of the neuromodulator $\mathrm{H}_{2} \mathrm{~S}$ by cystathionine $\beta$-synthase via the condensation of cysteine and homocysteine. J Biol Chem 279: 52082-52086, 2004.

14. Chen Y, Zhu C, Yang Z, Chen J, He Y, Jiao Y, He W, Qiu $\mathrm{L}$, Cen J, and Guo Z. A ratiometric fluorescent probe for rapid detection of hydrogen sulfide in mitochondria. Angew Chem Int Ed 52: 1688-1691, 2013.

15. Chiku T, Padovani D, Zhu W, Singh S, Vitvitsky V, and Banerjee $\mathrm{R}$. $\mathrm{H}_{2} \mathrm{~S}$ biogenesis by human cystathionine $\gamma$-lyase 
leads to novel sulfur metabolites lanthionine and homolanthionine and is responsive to the grade of hyperhomocysteinemia. J Biol Chem 284: 11601-11612, 2009.

16. Choi MG, Cha S, Lee H, Jeon HL, and Chang SK. Sulfideselective chemosignaling by a $\mathrm{Cu}^{2+}$ complex of dipicolylamine appended fluorescein. Chem Commun 7390-7392, 2009.

17. Corvino A, Severino B, Fiorino F, Frecentese F, Magli E, Perissutti E, Santagada V, Vucci M, Cirino G, Kelly G, Servillo L, Popowicz G, Pastore A, and Caliendo G. Fragment-based de novo design of a cystathionine $\gamma$-lyase selective inhibitor blocking hydrogen sulfide production. Sci Rep 6: 34398, 2016.

18. Dufton N, Natividad J, Verdu EF, and Wallace JL. Hydrogen sulfide and resolution of acute inflammation: a comparative study utilizing a novel fluorescent probe. Sci Rep 2: 4992012.

19. Faro MLL, Fox B, Whatmore JL, Winyard PG, and Whiteman M. Hydrogen sulfide and nitric oxide interactions in inflammation. Nitric Oxide 41: 38-47, 2014.

20. Fridkin M, Hazum E, Tauber-Finkelstein M, and Shaltiel S. Thiolysis of $O$-2,4-dinitrophenyltyrosines: spectrophotomeric monitoring of reaction and its use in peptide synthesis. Arch Biochem Biophys 178: 517-526, 1977.

21. Fukushima N, Ieda N, Kawaguchi M, Sasakura K, Nagano T, Hanaoka K, Miyata N, and Nakagawa H. Development of photo-controllable hydrogen sulfide donor applicable in live cells. Bioorg Med Chem Lett 25: 175-178, 2015.

22. Fukushima N, Ieda N, Sasakura K, Nagano T, Hanaoka K, Suzuki T, Naoki M, and Nakagawa H. Synthesis of a photocontrollable hydrogen sulfide donor using ketoprofenate photocages. Chem Commun 50: 587-589, 2014.

23. Gao M, Wang R, Yu FB, You JM, and Chen LX. A nearinfrared fluorescent probe for the detection of hydrogen polysulfides biosynthetic pathways in living cells and in vivo. Analyst 140: 3766-3772, 2015.

24. Gao M, Yu FB, Chen H, and Chen LX. Near-infrared fluorescent probe for imaging mitochondrial hydrogen polysulfides in living cells and in vivo. Anal Chem 87: 3631-3638, 2015.

25. Giepmans BN, Adams SR, Ellisman MH, and Tsien RY. The fluorescent toolbox for assessing protein location and function. Science 312: 217-224, 2006.

26. Gu X, Zhu H, Yang S, Zhu YC, and Zhu YZ. Development of a highly selective $\mathrm{H}_{2} \mathrm{~S}$ fluorescent probe and its application to evaluate CSE inhibitors. RSC Adv 4: 5009750101, 2014.

27. Hammers MD, Taormina MJ, Cerda MM, Montoya LA, Seidenkranz DT, Parthasarathy R, and Pluth MD. A bright fluorescent probe for $\mathrm{H}_{2} \mathrm{~S}$ enables analyte-responsive, 3D imaging in live zebrafish using light sheet fluorescence microscopy. J Am Chem Soc 137: 10216-10223, 2015.

28. Han Q, Mou Z, Wang H, Tang X, Dong Z, Wang L, Dong X, and Liu W. Highly selective and sensitive one- and twophoton ratiometric fluorescent probe for intracellular hydrogen polysulfide sensing. Anal Chem 88: 7206-7212, 2016.

29. Han X, Yu F, Song X, and Chen L. Quantification of cysteine hydropersulfide with a ratiometric near-infrared fluorescent probe based on selenium-sulfur exchange reaction. Chem Sci 7: 5098-5107, 2016.

30. Hanaoka K, Sasakura K, Suwanai Y, Toma-Fukai S, Shimamoto K, Takano Y, Shibuya N, Terai T, Komatsu T, Ueno T, Ogasawara Y, Tsuchiya Y, Watanabe Y, Kimura
H, Wang C, Uchiyama M, Kojima H, Okabe T, Urano Y, Shimizu T, and Nagano T. Discovery and mechanistic characterization of selective inhibitors of $\mathrm{H}_{2} \mathrm{~S}$-producing enzyme: 3-mercaptopyruvate sulfurtransferase (3MST) targeting active-site cysteine persulfide. Sci Rep 7: 40227, 2017.

31. Henthorn HA and Pluth MD. Mechanistic insights into the $\mathrm{H}_{2} \mathrm{~S}$-mediated reduction of aryl azides commonly used in $\mathrm{H}_{2} \mathrm{~S}$ detection. J Am Chem Soc 137: 15330-15336, 2015.

32. Hoffmann MR. Kinetics and mechanism of oxidation of hydrogen sulfide by hydrogen peroxide in acidic solution. Environ Sci Technol 11: 61-66, 1977.

33. Hou F, Huang L, Xi P, Cheng J, Zhao X, Xie G, Shi Y, Cheng F, Yao X, Bai D, and Zeng Z. A retrievable and highly selective fluorescent probe for monitoring sulfide and imaging in living cells. Inorg Chem 51: 2454-2460, 2012.

34. Hou Y, Yang XF, Zhong YG, and Li Z. Development of fluorescent probes for hydrogen polysulfides by using cinnamate ester as the recognition unit. Sensor Actuat B Chem 232: 531-537, 2016.

35. Huang Y, Yu FB, Wang JC, and Chen LX. Near-infrared fluorescence probe for in situ detection of superoxide anion and hydrogen polysulfides in mitochondrial oxidative stress. Anal Chem 88: 4122-4129, 2016.

36. Ida T, Sawa T, Ihara H, Tsuchiya Y, Watanabe Y, Kumagai Y, Suematsu M, Motohashi H, Fujii S, Matsunaga T, Yamamoto M, Ono K, Devarie-Baez NO, Xian M, Fukuto JM, and Akaike T. Reactive cysteine persulfides and Spolythiolation regulate oxidative stress and redox signaling. Proc Natl Acad Sci U S A 111: 7606-7611, 2014.

37. Ishii I, Akahoshi N, Yamada H, Nakano S, Izumi T, and Suematsu M. Cystathionine $\gamma$-lyase-deficient mice require dietary cysteine to protect against acute lethal myopathy and oxidative injury. J Biol Chem 285: 26358-26368, 2010.

38. Kaneko Y, Kimura Y, Kimura H, and Niki I. L-Cysteine inhibits insulin release from the pancreatic $\beta$-cell: possible involvement of metabolic production of hydrogen sulfide, a novel gasotransmitter. Diabetes 55: 1391-1397, 2006.

39. Kawagoe R, Takashima I, Uchinomiya S, and Ojida A. Reversible ratiometric detection of highly reactive hydropersulfides using a FRET-based dual emission fluorescent probe. Chem Sci [Epub ahead of print]; DOI: 10.1039/ C6SC03856E, 2017.

40. Kimura H. Physiological role of hydrogen sulfide and polysulfide in the central nervous system. Neurochem Int 63: 492-497, 2013.

41. Kimura H. Signaling molecules: hydrogen sulfide and polysulfide. Antioxid Redox Signal 22: 362-376, 2015.

42. Kimura H, Shibuya N, and Kimura Y. Hydrogen sulfide is a signaling molecules and a cytoprotectant. Antioxid Redox Signal 17: 45-57, 2012.

43. Klingerman CM, Trushin N, Prokopczyk B, and Haouzi P. $\mathrm{H}_{2} \mathrm{~S}$ concentrations in the arterial blood during $\mathrm{H}_{2} \mathrm{~S}$ administration in relation to its toxicity and effects on breathing. Am J Physiol Regul Integr Comp Physiol 305: R630-R638, 2013.

44. Kubáň V, Dasgupta PK, and Marx JN. Nitroprusside and methylene blue methods for silicone membrane differentiated flow injection determination of sulfide in water and wastewater. Anal Chem 64: 36-43, 1992. 
45. Li L, Bhatia M, Zhu YZ, Zhu YC, Ramnath RD, Wang ZJ, Anuar FB, Whiteman M, Salto-Tellez M, and Moore PK. Hydrogen sulfide is a novel mediator of lipopolysaccharideinduced inflammation in the mouse. FASEB $J$ 19: 11961198, 2005.

46. Lin VS, Lippert AR, and Chang CJ. Cell-trappable fluorescent probes for endogenous hydrogen sulfide signaling and imaging $\mathrm{H}_{2} \mathrm{O}_{2}$-dependent $\mathrm{H}_{2} \mathrm{~S}$ production. Proc Natl Acad Sci U S A 110: 7131-7135, 2013.

47. Lippert AR. Designing reaction-based fluorescent probes for selective hydrogen sulfide detection. J Inorg Biochem 133: 136-142, 2014.

48. Lippert AR, New EJ, and Chang CJ. Reaction-based fluorescent probes for selective imaging of hydrogen sulfide in living cells. J Am Chem Soc 133: 10078-10080, 2011.

49. Liu C, Chen W, Shi W, Peng B, Zhao Y, Ma H, and Xian M. Rational design and bioimaging applications of highly selective fluorescence probes for hydrogen polysulfides. $J$ Am Chem Soc 136: 7257-7260, 2014.

50. Liu C, Pan J, Li S, Zhao Y, Wu LY, Berkman CE, Whorton $\mathrm{AR}$, and Xian M. Capture and visualization of hydrogen sulfide by a fluorescent probe. Angew Chem Int Ed 50: 10327-10329, 2011.

51. Liu CR, Peng B, Li S, Park CM, Whorton AR, and Xian M. Reaction based fluorescent probes for hydrogen sulfide. Org Lett 14: 2184-2187, 2012.

52. Marutani E, Sakaguchi M, Chen W, Sasakura K, Liu J, Xian M, Hanaoka K, Nagano T, and Ichinose F. Cytoprotective effects of hydrogen sulfide-releasing $N$-methyl-Daspartate receptor antagonists mediated by intracellular sulfane sulfur. Med Chem Comm 5: 1577-1583, 2014.

53. Mikami Y, Shibuya N, Kimura Y, Nagahara N, Ogasawara $\mathrm{Y}$, and Kimura $\mathrm{H}$. Thioredoxin and dihydrolipoic acid are required for 3-mercaptopyruvate sufurtransferase to produce hydrogen sulfide. Biochem J 439: 479-485, 2011.

54. Montoya LA and Pluth MD. Selective turn-on fluorescent probes for imaging hydrogen sulfide in living cells. Chem Commun 48: 4767-4769, 2012.

55. Mustafa AK, Gadalla MM, Sen N, Kim S, Mu W, Gazi SK, Barrow RK, Yang G, Wang R, and Snyder SH. $\mathrm{H}_{2} \mathrm{~S}$ signals through protein S-sulfhydration. Sci Signal 2: ra72, 2009.

56. Nagahara N, Nagano M, Ito T, Shimamura K, Akimoto T, and Suzuki H. Antioxidant enzyme, 3-mercaptopyruvate sulfurtransferase-knockout mice exhibit increased anxietylike behaviors: a model for human mercaptolactate-cysteine disulfiduria. Sci Rep 3: 1986, 2013.

57. Nishida M, Sawa T, Kitajima N, Ono K, Inoue H, Ihara H, Motohashi H, Yamamoto M, Suematsu M, Kurose H, van der Vliet A, Freeman BA, Shibata T, Uchida K, Kumagai $\mathrm{Y}$, and Akaike T. Hydrogen sulfide anion regulates redox signaling via electrophile sulfhydration. Nat Chem Biol 8: 714-724, 2012.

58. Pak YL, Li J, Ko KC, Kim G, Lee JY, and Yoon J. Mitochondria-targeted reaction-based fluorescent probe for hydrogen sulfide. Anal Chem 88: 5476-5481, 2016.

59. Papapetropoulos A, Whiteman M, and Cirino G. Pharmacological tools for hydrogen sulphide research: a brief, introductory guide for beginners. $\mathrm{Br} J$ Pharmacol 172: 1633-1637, 2015.

60. Paul BD and Snyder $\mathrm{SH} . \mathrm{H}_{2} \mathrm{~S}$ signalling through protein sulfhydration and beyond. Nat Rev Mol Cell Biol 13: 499507, 2012.
61. Pearson RG. Hard and soft acids and bases. J Am Chem Soc 85: 3533-3539, 1963.

62. Peng B, Chen W, Liu C, Rosser EW, Pacheco A, Zhao Y, Aguilar HC, and Xian M. Fluorescent probes based on nucleophilic substitution-cyclization for hydrogen sulfide detection and bioimaging. Chem Eur J 20: 1010-1016, 2014.

63. Percudani $\mathrm{R}$ and Peracchi A. A genomic overview of pyridoxal-phosphate-dependent enzymes. EMBO Rep 4: 850-854, 2003.

64. Qian Y, Karpus J, Kabil O, Zhang SY, Zhu HL, Banerjee R, Zhao J, and He C. Selective fluorescent probes for live-cell monitoring of sulphide. Nat Commun 2: 495, 2011.

65. Qu XY, Li CJ, Chen HC, Mack J, Guo ZJ, and Shen Z. A red fluorescent turn-on probe for hydrogen sulfide and its application in living cells. Chem Commun 49: 7510-7512, 2013.

66. Reiffenstein RJ, Hulbert WC, and Roth SH. Toxicology of hydrogen sulfide. Annu Rev Pharmacol Toxicol 32: 109134, 1992.

67. Sasakura K, Hanaoka K, Shibuya N, Mikami Y, Kimura Y, Komatsu T, Ueno T, Terai T, Kimura H, and Nagano T. Development of a highly selective fluorescence probe for hydrogen sulfide. J Am Chem Soc 133: 18003-18005, 2011.

68. Schreiber SL, Kotz JD, Li M, Aubé J, Austin CP, Reed JC, Rosen H, White EL, Sklar LA, Lindsley CW, Alexander BR, Bittker JA, Clemons PA, de Souza A, Foley MA, Palmer M, Shamji AF, Wawer MJ, McManus O, Wu M, Zou B, Yu H, Golden JE, Schoenen FJ, Simeonov A, Jadhav A, Jackson MR, Pinkerton AB, Chung TDY, Griffin PR, Cravatt BF, Hodder PS, Roush WR, Roberts E, Chung DH, Jonsson CB, Noah JW, Severson WE, Ananthan S, Edwards B, Oprea TI, Conn PJ, Hopkins CR, Wood MR, Stauffer SR, Emmitte KA, and NIH Molecular Libraries Project Team. Advancing biological understanding and therapeutics discovery with small-molecule probes. Cell 161: 1252-1265, 2015.

69. Scriven EFV and Turnbull K. Azides-their preparation and synthetic uses. Chem Rev 88: 297-368, 1988.

70. Shang HM, Chen H, Tang YH, Guo R, and Lin WY. Construction of a two-photon fluorescent turn-on probe for hydrogen persulfide and polysulfide and its bioimaging application in living mice. Sensor Actuat B Chem 230: 773778, 2016.

71. Shimamoto K and Hanaoka K. Fluorescent probes for hydrogen sulfide $\left(\mathrm{H}_{2} \mathrm{~S}\right)$ and sulfane sulfur and their applications to biological studies. Nitric Oxide 46: 72-79, 2015.

72. Sun Q, Collins R, Huang S, Holmverg-Schiavone L, Anand GS, Tan CH, van-den-Berg S, Deng LW, Moore PK, Karlberg T, and Sivaraman J. Structural basis for the inhibition mechanism of human cystathionine $\gamma$-lyase, an enzyme responsible for the production of $\mathrm{H}_{2} \mathrm{~S}$. J Biol Chem 284: 3076-3085, 2009.

73. Takano Y, Hanaoka K, Shimamoto K, Miyamoto R, Komatsu T, Ueno T, Terai T, Kimura H, Nagano T, and Urano Y. Development of a reversible fluorescent probe for reactive sulfur species, sulfane sulfur, and its biological application. Chem Commun 53: 1064-1067, 2017.

74. Takano Y, Shimamoto K, and Hanaoka K. Chemical tools for the study of hydrogen sulfide $\left(\mathrm{H}_{2} \mathrm{~S}\right)$ and sulfane sulfur and their applications to biological studies. J Clin Biochem Nutr 58: 7-15, 2016.

75. Thorson MK, Majtan T, Kraus JP, and Barrios AM. Identification of cystathionine $\beta$-synthase inhibitors using a 
hydrogen sulfide selective probe. Angew Chem Int Ed 52: 4641-4644, 2013.

76. Toohey JI. Sulfur signaling: is the agent sulfide or sulfane? Anal Biochem 413: 1-7, 2011.

77. Tsai DM, Kumar AS, and Zen JM. A highly stable and sensitive chemically modified screen-printed electrode for sulfide analysis. Anal Chim Acta 556: 145-150, 2006.

78. Ueno $T$ and Nagano $T$. Fluorescent probes for sensing and imaging. Nat Method 8: 642-645, 2011.

79. Watanabe M, Osada J, Aratani Y, Kluckman K, Reddick R, Malinow MR, and Maeda N. Mice deficient in cystathionine $\beta$-synthase: animal models for mild and severe homocyst(e)inemia. Proc Natl Acad Sci U S A 92: 15851589, 1995.

80. Wei L, Yi L, Song F, Wei C, Wang B, and Xi Z. FRET ratiometric probes reveal the chiral-sensitive cysteinedependent $\mathrm{H}_{2} \mathrm{~S}$ production and regulation in living cells. Sci Rep 4: 4521, 2014.

81. Whiteman M, Trionnaire SL, Chopra M, Fox B, and Whatmore J. Emerging role of hydrogen sulfide in health and disease: critical appraisal of biomarkers and pharmacological tools. Clin Sci 121: 459-488, 2011.

82. Wood JL. Sulfane sulfur. Methods Enzymol 143: 25-29, 1987.

83. Xu Z, Xu L, Zhou J, Xu YF, Zhu WP, and Qian XH. A highly selective fluorescent probe for fast detection of hydrogen sulfide in aqueous solution and living cells. Chem Commun 48: 10871-10873, 2012.

84. Yadav PK, Martinov M, Vitvitsky V, Seravalli J, Wedmann R, Filipovic MR, and Banerjee R. Biosynthesis and reactivity of cysteine persulfides in signaling. J Am Chem Soc 138: 289-299, 2016.

85. Yang G, Wu L, Jiang B, Yang W, Qi J, Cao K, Meng Q, Mustafa AK, Mu W, Zhang S, Snyder SH, and Wang R. $\mathrm{H}_{2} \mathrm{~S}$ as a physiologic vasorelaxant: hypertension in mice with deletion of cystathionine $\gamma$-lyase. Science 322: 587590, 2008.

86. Yi L, Wei L, Wang R, Zhang C, Zhang J, Tan T, and Xi Z. A dual-response fluorescent probe reveals the $\mathrm{H}_{2} \mathrm{O}_{2}$-induced $\mathrm{H}_{2} \mathrm{~S}$ biogenesis through a cystathionine $\beta$-synthase pathway. Chem Eur J 21: 15167-15172, 2015.

87. Yu F, Han X, and Chen L. Fluorescent probes for hydrogen sulfide detection and bioimaging. Chem Commun 50: 12234-12249, 2014.

88. Yu F, Li P, Song P, Wang B, Zhao J, and Han K. An ICTbased strategy to a colorimetric and ratiometric fluorescence probe for hydrogen sulfide in living cells. Chem Commun 48: 2852-2854, 2012.
89. Zeng LY, Chen SY, Xia T, Hu W, Li CY, and Liu ZH. Two-photon fluorescent probe for detection of exogenous and endogenous hydrogen persulfide and polysulfide in living organisms. Anal Chem 87: 3004-3010, 2015.

Address correspondence to: Prof. Kenjiro Hanaoka Graduate School of Pharmaceutical Sciences The University of Tokyo 7-3-1, Hongo, Bunkyo-ku Tokyo 113-0033 Japan

E-mail: khanaoka@mol.f.u-tokyo.ac.jp

Date of first submission to ARS Central, March 22, 2017; date of acceptance, April 10, 2017.

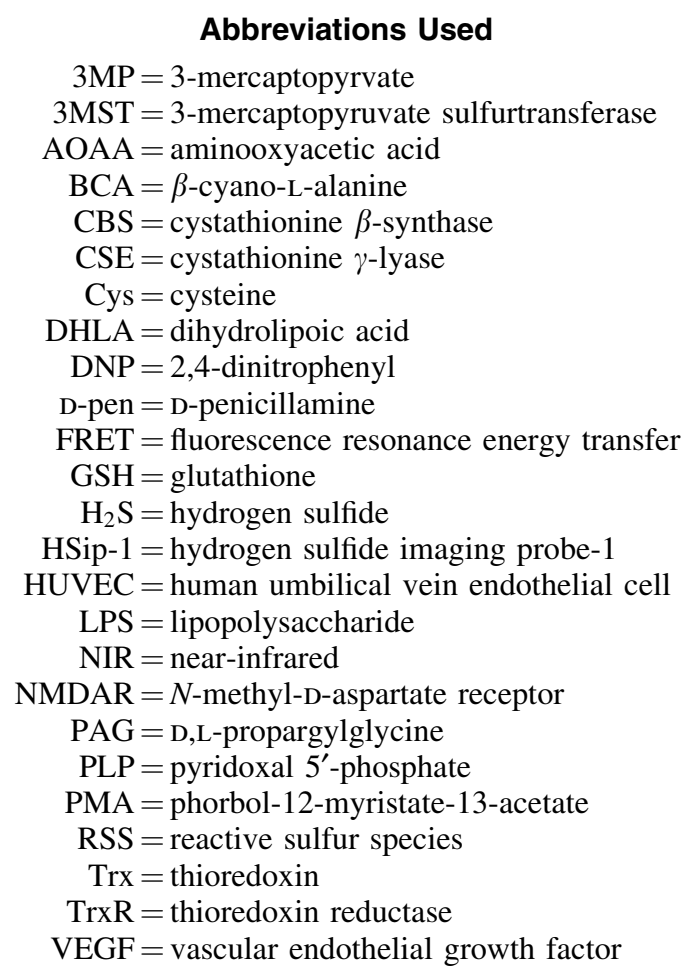

